\title{
Clinical Pharmacokinetics and Pharmacodynamics of Telavancin Compared with the Other Glycopeptides
}

\author{
Valentin al Jalali $^{1} \cdot$ Markus Zeitlinger $^{1}$
}

Published online: 13 January 2018

(C) The Author(s) 2018. This article is an open access publication

\begin{abstract}
Telavancin was discovered by modifying the chemical structure of vancomycin and belongs to the group of lipoglycopeptides. It employs its antimicrobial potential through two distinct mechanisms of action: inhibition of bacterial cell wall synthesis and induction of bacterial membrane depolarization and permeabilization. In this article we review the clinically relevant pharmacokinetic and pharmacodynamic data of telavancin. For comparison, the pharmacokinetic and pharmacodynamic data of the other glycopeptides are presented. Although, in contrast to the newer lipoglycopeptides, telavancin demonstrates a relatively short half-life and rapid total clearance, its apparent volume of distribution $\left(V_{\mathrm{d}}\right)$ is almost identical to that of dalbavancin. The accumulation of telavancin after repeated dosing is only marginal, whereas the pharmacokinetic values of the other glycopeptides show much greater differences after administration of multiple doses. Despite its high plasma-protein binding of $90 \%$ and relatively low $V_{\mathrm{d}}$ of approximately $11 \mathrm{~L}$, telavancin shows near complete equilibration of the free fraction in plasma with soft tissue. The ratio of the area under the plasma concentration-time curve from time zero to $24 \mathrm{~h}\left(\mathrm{AUC}_{24}\right)$ of unbound plasma concentrations to the minimal inhibitory concentration (MIC) required to inhibit growth of $90 \%$ of organisms $\left(\mathrm{MIC}_{90}\right)$ of Staphylococcus aureus and S. epidermidis of telavancin are sufficiently high to achieve pharmacokinetic/pharmacodynamic targets indicative for optimal bacterial killing. Considering both the $\mathrm{AUC}_{24} / \mathrm{MIC}$
\end{abstract}

Markus Zeitlinger

markus.zeitlinger@meduniwien.ac.at;

http://www.meduniwien.ac.at/klpharm/

1 Department of Clinical Pharmacology, Medical University of Vienna, Waehringer Guertel 18-20, 1090 Vienna, Austria ratios of telavancin and the near complete equilibration of the free fraction in plasma with soft tissue, telavancin is an appropriate antimicrobial agent to treat soft tissue infections caused by Gram-positive pathogens. Although the penetration of telavancin into epithelial lining fluid (ELF) requires further investigations, the $\mathrm{AUC}_{24} / \mathrm{MIC}$ ratio for S. aureus indicates that bactericidal activity in the ELF could be expected.

\section{Key Points}

Multiple dosing does only lead to slight accumulation of telavancin in blood.

The pharmacokinetic and pharmacodynamic properties of telavancin make it an effective treatment option for soft tissue infections caused by Gram-positive organisms.

Further studies are needed to explore the pharmacokinetic and pharmacodynamic properties of telavancin in epithelial lining fluid.

\section{Introduction}

In the early 1950s, vancomycin was discovered as the first antibiotic belonging to the glycopeptide group. Since then, the incidence of bacterial resistance to various kinds of antimicrobial agents has increased tremendously [1]. Although the population-weighted mean percentage of methicillin-resistant Staphylococcus aureus (MRSA) has 
been declining in recent years in Europe, it had been on a dramatic upward trend for decades and remains threateningly high today in many countries [2-6]. In an analysis of resistance patterns of $S$. aureus isolates from intensive care units in the USA, an increase in the proportion of MRSA from $35.9 \%$ in 1992 to $64.4 \%$ in 2003 was found [4]. In contrast, a more recent survey from Germany studied data from all clinical settings, including outpatient settings, and demonstrated a decline in the proportion of MRSA in $S$. aureus isolates from $15 \%$ in 2010 to $10 \%$ in 2015 [3]. Unfortunately, the prevalence of community-associated MRSA (CA-MRSA) infections is constantly rising and there is evidence that healthcare-associated infections may increasingly be caused by CA-MRSA [7, 8]. Moreover, vancomycin-intermediate $S$. aureus (VISA), heteroresistant VISA (hVISA), and even vancomycin-resistant $S$. aureus (VRSA) are isolated with increasing frequency from clinical samples [9, 10]. Another threat is the rising number of vancomycin-resistant Enterococci (VRE; mainly Enterococcus faecalis and E. faecium) in cultures obtained from clinical isolates $[5,6,11]$.

Since vancomycin remains one of the foremost treatment options for infections caused by Gram-positive pathogens with resistance against $\beta$-lactams, the decrease in susceptibility to vancomycin has led to the development of alternative antibiotic agents. Teicoplanin, the second member of the group of glycopeptides, was isolated in 1984 from fermentation products of Actinoplanes teichomyceticus and no further glycopeptide was discovered for 16 years [12]. In the hope of finding more potent antibiotics, the chemical structure of vancomycin has been modified in a variety of ways. By adding a lipophilic side chain and an aminomethyl phosphonite group, telavancin was successfully developed from vancomycin [13, 14]. This structural modification is responsible for the divergent pharmacokinetic and pharmacodynamic properties of telavancin, such as its enhanced lipophilicity and therefore superior membrane penetration, increased antimicrobial activity in vitro against various Gram-positive pathogens, and reduced development of resistance.

Telavancin was discovered in 2000 and became available on the market as the first lipoglycopeptide antibiotic in 2009 in the USA for the treatment of complicated skin and skin-structure infections (cSSSIs). Subsequently, in 2013 telavancin was approved for the treatment of hospital-acquired bacterial pneumonia (HABP) and ventilator-associated bacterial pneumonia (VABP) in the USA. In the European Union, telavancin was approved by the European Medicines Agency (EMA) in 2014 for the treatment of adults with nosocomial pneumonia, including VABP, known or suspected to be caused by MRSA [15]. Soon after the discovery of telavancin, other lipoglycopeptide antibiotics were developed through modification of the chemical structure of vancomycin and teicoplanin. Dalbavancin and oritavancin are the two other lipoglycopeptides, which were consecutively developed and successfully approved by the Food and Drug Administration (FDA) in the USA. Dalbavancin was also approved by the EMA in 2014 for the treatment of acute bacterial skin and skin structure infections (ABSSSIs) in adults and oritavancin was granted approval by the EMA in 2015 for the same indication [16, 17]. A summary of the indications of the lipoglycopeptides can be found in Table 1.

In this review we present the clinically relevant pharmacokinetic and pharmacodynamic data of telavancin and compare it with the available data of the other members of the glycopeptide group, namely vancomycin, teicoplanin, dalbavancin, and oritavancin.

\section{Methods}

For this review we performed an extensive and systematic search for pharmacokinetic and pharmacodynamic data on glycopeptides in humans. Studies from the PubMed US National Library of Medicine database up until July 2017 were included. We then selected the studies that most accurately display the approved or recommended dosing patterns (see Table 2) and provide the most relevant and detailed pharmacokinetic data. To ensure a thorough comparison of the discussed substances, the missing pharmacokinetic parameters were calculated using Eq. (1):

$t_{1 / 2}=\frac{\ln 2}{k_{\mathrm{e}}}$,

where $k_{\mathrm{e}}$ is the elimination rate constant and $t_{1 / 2}$ is the terminal elimination half-life in hours.

Missing values of the area under the plasma concentration-time curve (AUC) from time zero to $24 \mathrm{~h}\left(\mathrm{AUC}_{24}\right)$ or the AUC from time zero to infinity $\left(\mathrm{AUC}_{\infty}\right)$ were derived using Eqs. (2) and (3):

$\mathrm{AUC}_{24}=\mathrm{AUC}_{\infty}-\mathrm{AUC}_{24-\infty}$,

where $\mathrm{AUC}_{24-\infty}$ represents the AUC from $24 \mathrm{~h}$ to infinity.

$\mathrm{AUC}_{24-\infty}=\frac{C_{24}}{k_{\mathrm{e}}}$,

where $C_{24}$ represents the plasma drug-concentration after $24 \mathrm{~h}$.

Missing values of the apparent volume of distribution $\left(V_{\mathrm{d}}\right)$ and total clearance $\left(\mathrm{CL}_{\mathrm{total}}\right)$ were calculated using Eq. (4):

$\mathrm{CL}_{\text {total }}=V_{\mathrm{d}} \times k_{\mathrm{e}}$. 
Table 1 Therapeutic indications for the different lipoglycopeptides as approved by the US Food and Drug Administration and European Medicines Agency

EMA FDA

Telavancin Adults with nosocomial pneumonia, including VABP, cSSSIs; HABP/VABP caused by susceptible isolates of Staphylococcus known or suspected to be caused by MRSA

Dalbavancin ABSSSIs in adults aureus

Adult patients with ABSSSIs caused by designated susceptible strains of Gram-positive micro-organisms

Oritavancin ABSSSIs in adults

Adult patients with ABSSSIs caused or suspected to be caused by susceptible isolates of designated Gram-positive micro-organisms

ABSSSIs acute bacterial skin and skin structure infections, CSSSIs complicated skin and skin-structure infections, EMA European Medicines Agency, FDA US Food and Drug Administration, HABP hospital-acquired bacterial pneumonia, MRSA methicillin-resistant Staphylococcus aureus, $V A B P$ ventilator-associated bacterial pneumonia

Table 2 Dosing schemes recommended by the manufacturer

\begin{tabular}{|c|c|c|c|c|c|c|}
\hline \multirow[t]{2}{*}{ Drug } & \multirow{2}{*}{$\begin{array}{l}\text { Renal status }\left(\mathrm{CL}_{\mathrm{CR}}\right. \\
[\mathrm{mL} / \mathrm{min}])\end{array}$} & \multicolumn{4}{|l|}{ Dose } & \multirow[t]{2}{*}{$\mathrm{PB}(\%)$} \\
\hline & & $\mathrm{mg}$ & $\mathrm{mg} / \mathrm{kg}$ & $\mathrm{mg} / 24 \mathrm{~h}$ & Dosing pattern & \\
\hline \multirow[t]{3}{*}{ Telavancin } & $>50$ & & 10 & & od & 90 \\
\hline & $30-50$ & & 7.5 & & od & \\
\hline & $<30$ & & $\begin{array}{l}\text { Not } \\
\text { indicated }\end{array}$ & & & \\
\hline \multirow[t]{4}{*}{ Dalbavancin } & $\begin{array}{l}\geq 30 \text { or } \\
\text { hemodialysis }\end{array}$ & 1500 & & & Single & 93 \\
\hline & & $\begin{array}{l}1000 \mathrm{LD} \\
500 \mathrm{MD}\end{array}$ & & & ow & \\
\hline & $\begin{array}{l}<30 \text { and no } \\
\text { hemodialysis }\end{array}$ & 1000 & & & Single & \\
\hline & & $\begin{array}{l}750 \mathrm{LD}, 375 \\
\mathrm{MD}\end{array}$ & & & ow & \\
\hline \multirow[t]{2}{*}{ Oritavancin } & $\geq 30$ & 1200 & & & Single & 85 \\
\hline & $\begin{array}{l}<30 \text { or } \\
\text { hemodialysis }\end{array}$ & $\begin{array}{l}\text { No data } \\
\text { available }\end{array}$ & & & & \\
\hline \multirow[t]{3}{*}{ Vancomycin } & $>100$ & & & $1500-2000$ & $2-4$ doses/day & $30-55$ \\
\hline & $100-70$ & & & $1000-1500$ & 2-3 doses/day & \\
\hline & $70-30$ & & & $500-1000$ & 1-2 doses/day & \\
\hline \multirow[t]{6}{*}{ Teicoplanin } & $>80$ & & 6 & & Bid for $36 \mathrm{~h}$, then od & $87.6-90.8$ \\
\hline & & & 12 & & Bid for $36-60 \mathrm{~h}$, then od & \\
\hline & $80-30$ & & $\begin{array}{l}6 \mathrm{LD}, 3 \\
\mathrm{MD}\end{array}$ & & $\begin{array}{l}\text { LD bid for } 36 \mathrm{~h} \text {, then od; from day } 4 \mathrm{MD} \text { od or } \mathrm{LD} \\
\text { every second day }\end{array}$ & \\
\hline & & & $\begin{array}{l}12 \mathrm{LD}, 6 \\
\mathrm{MD}\end{array}$ & & $\begin{array}{l}\text { LD bid for } 36-60 \mathrm{~h} \text {, then od; from day } 4 \mathrm{MD} \text { od or } \\
\text { LD every second day }\end{array}$ & \\
\hline & $\begin{array}{l}<30 \text { or } \\
\text { hemodialysis }\end{array}$ & & $\begin{array}{l}6 \mathrm{LD}, 2 \\
\mathrm{MD}\end{array}$ & & $\begin{array}{l}\text { LD bid for } 36 \mathrm{~h} \text {, then od; from day } 4 \mathrm{MD} \text { od or } \mathrm{LD} \\
\text { every third day }\end{array}$ & \\
\hline & & & $\begin{array}{l}12 \mathrm{LD}, 4 \\
\mathrm{MD}\end{array}$ & & $\begin{array}{l}\text { LD bid for } 36-60 \mathrm{~h} \text {, then od; from day } 4 \mathrm{MD} \text { od or } \\
\text { LD every third day }\end{array}$ & \\
\hline
\end{tabular}

bid twice daily, $C L_{C R}$ creatinine clearance, $L D$ loading dose, $M D$ maintenance dose, $P B$ protein binding, $o d$ once daily, ow once weekly 


\section{Chemistry and Mechanism of Action}

Telavancin, a lipoglycopeptide, belongs to the group of glycopeptide antibiotics and is a semi-synthetic substance derived from the glycopeptide vancomycin. It is modified from vancomycin by addition of a lipophilic side chain and an aminomethyl phosphonite group and is therefore characterized as a lipoglycopeptide [13, 14]. Figure 1 depicts the structural formula of all available glycopeptides.
Telavancin has a relatively high molecular weight of $1755.63 \mathrm{~g} / \mathrm{mol}$ and is poorly soluble in water. The only available intravenous formulation, named Vibativ ${ }^{\circledR}$, has been modified with the solubilizer hydroxypropylbetadex (HP- $\beta-C D)$ to enhance solubility [14].

Despite its structural similarity to vancomycin, telavancin deploys its antimicrobial activity through two different mechanisms. The first mechanism, inhibition of bacterial cell wall synthesis, is shared by all glycopeptide

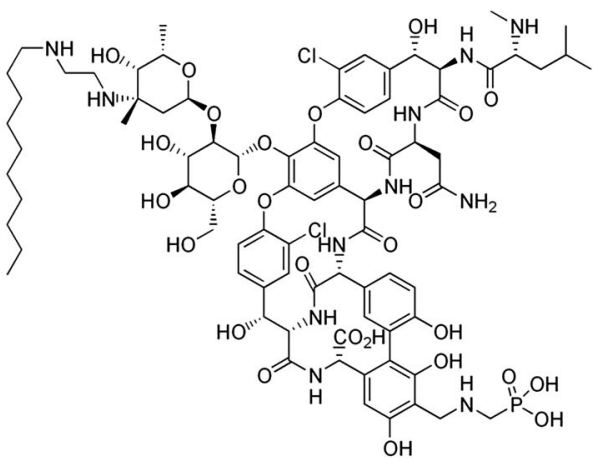

Telavancin

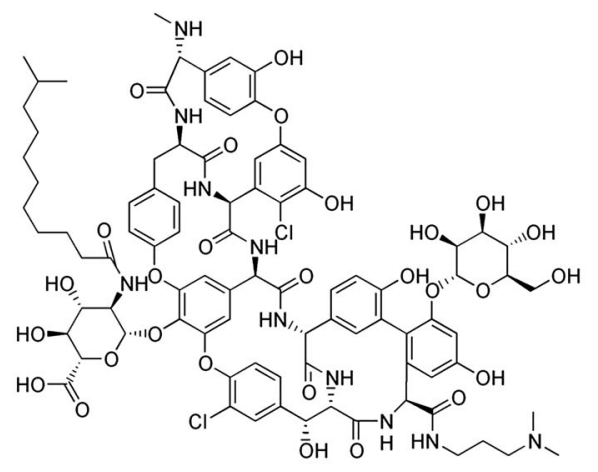

Dalbavancin

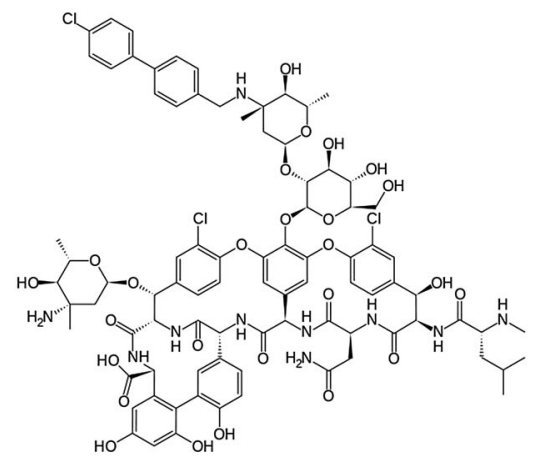

Oritavancin
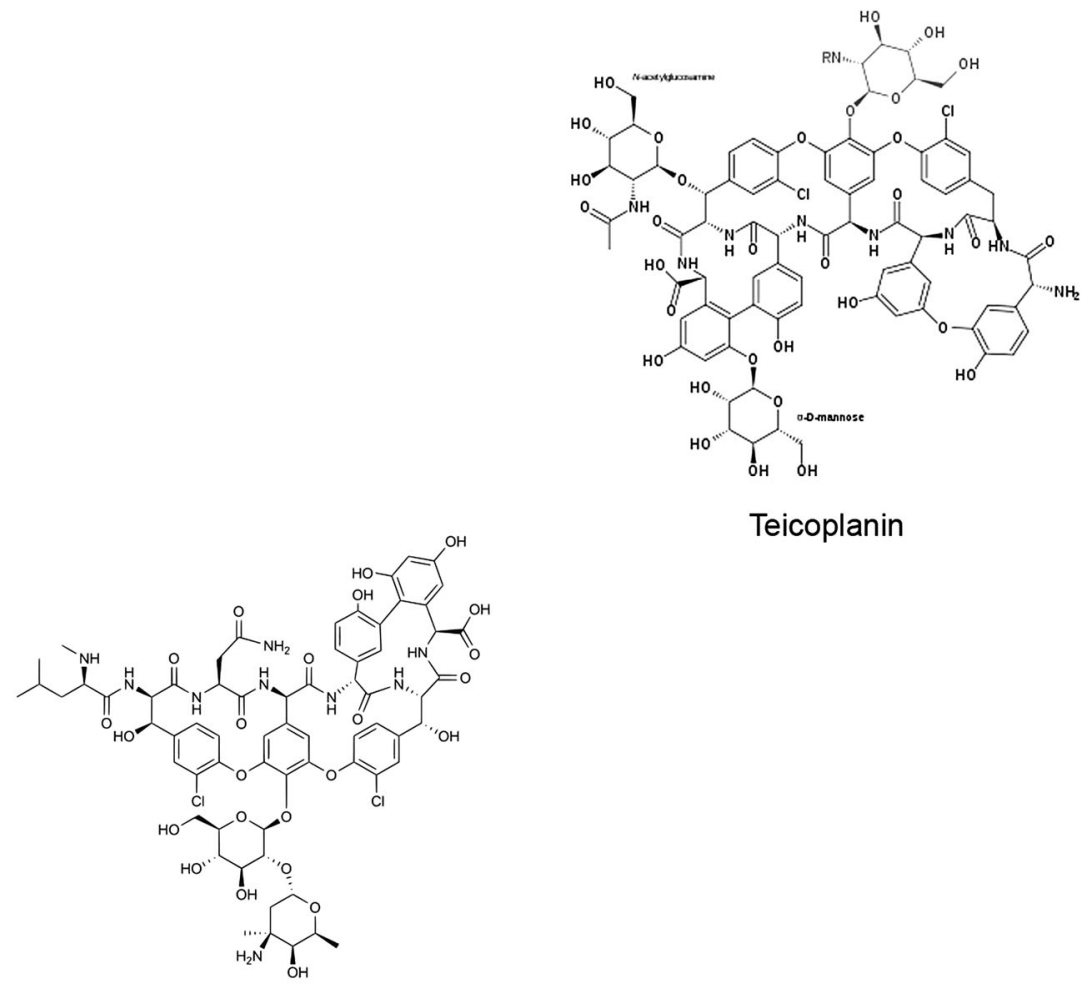

Teicoplanin

Vancomycin

Fig. 1 Chemical structures of all available glycopeptides, namely telavancin, dalbavancin, oritavancin, teicoplanin, and vancomycin. Figures are taken from Wikipedia (https://en.wikipedia.org) 
antibiotics. By binding to the D-alanyl-D-alanine (D-Ala-DAla) terminus of peptidoglycan precursors, they inhibit peptidoglycan cross-linking and consequently bacterial cell wall synthesis. The second mechanism of antimicrobial activity of telavancin is achieved by bacterial membrane depolarization and permeabilization and is not shared with vancomycin $[18,19]$.

To perform its antimicrobial activity, telavancin and all the other glycopeptides have to reach the murein synthases within the inner membrane of the bacterial cell wall. Due to the specific differences in bacterial structure, glycopeptides are not able to reach the target site in Gram-negative bacteria. Therefore, their antibacterial activity is limited to Gram-positive bacteria.

Acquired resistance of enterococci to glycopeptides is induced by plasmid-mediated expression of Van operons. To date, nine different operons have been identified, of which $\operatorname{Van} A$ and $\operatorname{Van} B$ are the most frequently encountered operons in VRE [20, 21]. These operons encode for enzymes that modify the peptidoglycan precursor D-Ala-DAla dipeptide and thereby substantially decrease the affinity of vancomycin to its target site (up to 1000-fold) $[22,23]$.

The VanA operon encodes for three different enzymes (VanH, VanA, and VanX) that are responsible for the replacement of D-Ala-D-Ala with D-alanyl-D-lactate (D-Ala$\mathrm{D}-\mathrm{Lac}$ ) at the peptidoglycan precursor. VanX is one of these enzymes and its activity has been utilized to measure the induction of resistance to glycopeptides in enterococci. Telavancin, teicoplanin, and vancomycin induce VanX activity in VanA-type strains to a similar extent. However, the average minimal inhibitory concentration (MIC) of telavancin for these VRE is significantly lower than those of vancomycin and teicoplanin (32- and 128-fold, respectively) [22]. The VanB operon encodes for three functionally equivalent enzymes to VanH, VanA, and VanX. In contrast to vancomycin, telavancin and teicoplanin do not induce VanX activity in VanB-type strains, which is why $V a n B$-type enterococci remain susceptible to them [24]. Resistance of VanC-type enterococci to vancomycin is attained by enzymes that replace the D-Ala-D-Ala at the peptidoglycan precursors with D-alanyl-D-serine (D-Ala-DSer) and thus reduce the affinity of vancomycin to its binding site. In contrast to other resistance types, VanCtype resistance is believed not to be acquired but to be intrinsic to E. gallinarum, E. flavescens, and E. casseliflavus. However, recent studies identified the VanC gene in an E. faecium strain and therefore suggest that even VanC-type resistance can be transferred from one species to another. Activity of telavancin against VanC-type enterococci has not been investigated yet, but teicoplanin remains potent against them [21-23, 25-30].
Resistance of $S$. aureus to vancomycin has only been detected in strains carrying the VanA operon. In these $S$. aureus strains the VanA resistance genes are transferred from enterococci, leading to isolates with moderate to high levels of resistance to vancomycin. Susceptibility to telavancin is reduced in these strains but the MIC remains much lower than that of vancomycin [10, 31-33].

\section{Pharmacokinetics}

\subsection{Pharmacokinetics in Plasma}

\subsubsection{After Single-Dose Administration}

Table 3 summarizes the pharmacokinetics of all members of the group of glycopeptides in healthy individuals after single-dose administration according to the currently recommended dosing schemes as displayed in Table 2.

The group of glycopeptide antibiotics is very inhomogeneous regarding pharmacokinetics. The half-life $\left(t^{1 / 2}\right)$ varies from $4.48 \mathrm{~h}$ for vancomycin and $6.5 \mathrm{~h}$ for telavancin to $192.3 \mathrm{~h}$ for dalbavancin. At first sight the pharmacokinetics of telavancin $(10 \mathrm{mg} / \mathrm{kg})$ closely resemble the pharmacokinetics of vancomycin (1000 mg) with an almost identical maximum concentration $\left(C_{\max }\right)$ [76.7 vs. $74.6 \mathrm{mg} / \mathrm{L}]$. However, the $t_{1 / 2}$ of telavancin is moderately higher $(6.5$ vs. $4.95 \mathrm{~h})$ with a distinctly lower total clearance $(1.19$ vs. $5.79 \mathrm{~L} / \mathrm{h})$ and $V_{\mathrm{d}}(10.88$ vs. $40.7 \mathrm{~L})$. We found no studies that evaluated the $\mathrm{AUC}_{24}$ or $\mathrm{AUC}_{\infty}$ after single-dose administration of vancomycin to healthy individuals. Dalbavancin $(1000 \mathrm{mg})$ shows the longest $t_{1 / 2}$ of the glycopeptides $\left[192.3 \mathrm{~h}\right.$ ] and a much higher $C_{\max }$ than telavancin $(299$ vs. $76.7 \mathrm{mg} / \mathrm{L})$. The $\mathrm{AUC}_{\infty}$ of dalbavancin is almost five times than that of telavancin $(24,745$ vs. $539 \mathrm{mg} \cdot \mathrm{h} / \mathrm{L}$ ), and the $\mathrm{AUC}_{24}$ is approximately seven times that of telavancin $(3342.25$ vs. $482.7 \mathrm{mg} \cdot \mathrm{h} / \mathrm{L})$. The substantially longer $t_{1 / 2}$ and higher AUC values of dalbavancin can be explained by the considerably lower total clearance of dalbavancin $(0.0404$ vs. $1.19 \mathrm{~L} / \mathrm{h})$ with a similar $V_{\mathrm{d}}$ $(11.21$ vs. $10.88 \mathrm{~L})$. Teicoplanin shows similar $C_{\max }$, $\mathrm{AUC}_{\infty}$, and total clearance values to telavancin, but a markedly longer $t_{1 / 2}(44.12$ vs. $6.5 \mathrm{~h})$. This may be explained by the large $V_{\mathrm{d}}$ of teicoplanin (41.73 vs. 10.88 L). Only limited data for oritavancin are available; therefore, we had to include data for a reduced dose of $800 \mathrm{mg}$. For this dose, oritavancin demonstrates an approximately two-fold higher $C_{\max }(137$ vs. $67.7 \mathrm{mg} / \mathrm{L})$ and $\mathrm{AUC}_{24}$ (1111 vs. $482.7 \mathrm{mg} \cdot \mathrm{h} / \mathrm{L}$ ) than telavancin [34-38].

The main route of elimination of telavancin is renal excretion. In a study with a single dose of radiolabeled telavancin, $76 \%$ of the dose was recovered in the urine and 


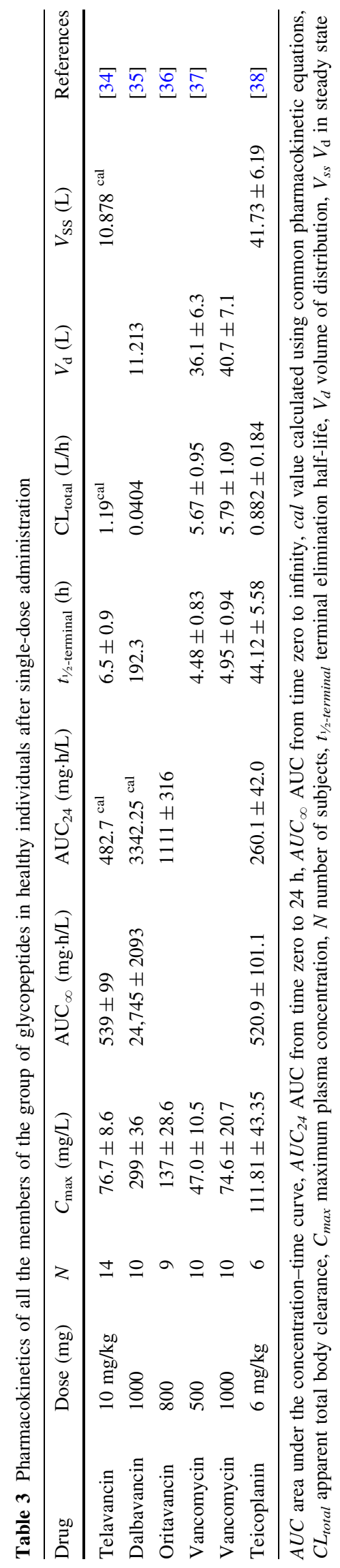

only $1 \%$ in feces. Most of the dose (83\%) collected in urine after $48 \mathrm{~h}$ was excreted unchanged [39].

\subsubsection{After Multiple-Dose Administration}

Table 4 summarizes the pharmacokinetics of the different glycopeptides after multiple-dose administration in healthy individuals. Again, the selected studies resemble the recommended doses by the manufacturer as accurately as possible.

The pharmacokinetic parameters of telavancin after administration of $10 \mathrm{mg} / \mathrm{kg}$ bodyweight (BW) once daily are similar to those after single-dose administration. The $C_{\max }, \mathrm{AUC}_{\infty}$, and $\mathrm{AUC}_{24}$ increase by less than twofold and the $t_{1 / 2}$ slightly increases from 6.5 to $7.41 \mathrm{~h}$ compared with single dose-administration. Once-daily administration of $10 \mathrm{mg} / \mathrm{kg}$ BW represents the recommended dosing pattern of telavancin by the manufacturer for patients with a creatinine clearance above $50 \mathrm{~mL} / \mathrm{min}$.

The $t_{1 / 2}$ values of dalbavancin (1000 mg loading dose and $500 \mathrm{mg}$ maintenance dose), teicoplanin $(6 \mathrm{mg} / \mathrm{kg}$ $\mathrm{BW}$ ), and vancomycin (500 mg four times per day) are substantially higher after multiple-dose administration than single-dose administration, rising from 193.1 to $321 \mathrm{~h}$ for dalbavancin, from 44.12 to $159 \mathrm{~h}$ for teicoplanin, and from 4.48 to $8.1 \mathrm{~h}$ for vancomycin. For dalbavancin the manufacturer recommends a loading dose of $1000 \mathrm{mg}$ and a weekly maintenance dose of $500 \mathrm{mg}$ for patients with a creatinine clearance $\geq 30 \mathrm{~mL} / \mathrm{min}$ or hemodialysis patients. The pharmacokinetic parameters shown in Table 4 were accomplished after this standard dose. Multiple-dose administration of oritavancin is not recommended by the manufacturer, but in Table 4 we show pharmacokinetic data after oritavancin $200 \mathrm{mg}$ once daily for 3 days for comparison with the other glycopeptides. The doses of teicoplanin and vancomycin employed in the cited studies are in accordance with the recommended dosing patterns for patients without organ impairment. However, there are no published data evaluating the $\mathrm{AUC}_{24}$ or $\mathrm{AUC}_{\infty}$ in healthy individuals after multiple-dose administration of teicoplanin or vancomycin [36, 40-43].

\subsection{Pharmacokinetics in Relevant Tissues}

Telavancin is approved for the treatment of cSSSIs and for the treatment of HABP, including VABP. Therefore, we concentrated on pharmacokinetic studies regarding soft tissues and tissues of the lung (epithelial lining fluid [ELF] or alveolar macrophages).

In Table 5 we present pharmacokinetic data in muscle, subcutaneous tissue, blister fluid, and ELF. Microdialysis enables continuous determination of the concentrationtime profile in the interstitial space fluid, which is regarded 


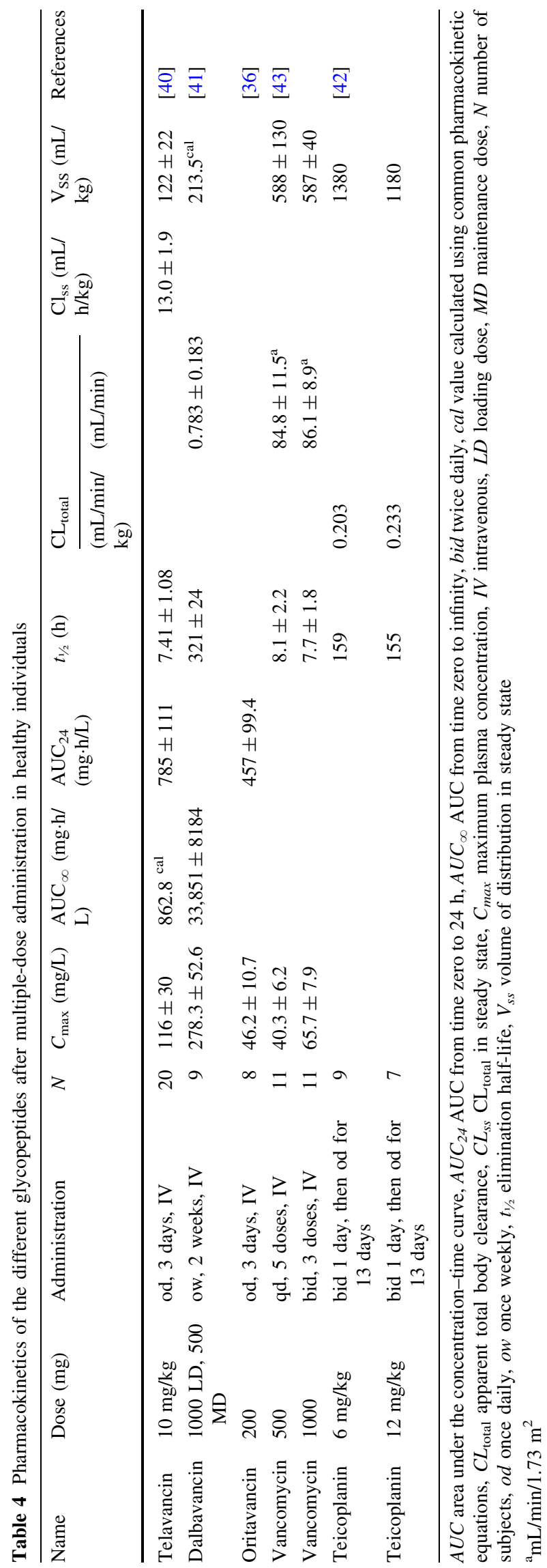

to resemble the target site compartment of the antimicrobial agents more closely than plasma [44]. Similarly, blister fluid is frequently used for this purpose; however, the appropriateness of this approach is controversial as skin blister represents an artificial compartment and continuous sampling is not possible. Since no pharmacokinetic studies for vancomycin for healthy tissue are available, we provided data from patients with lower limb infections for comparison. Data of the different glycopeptides can therefore only be compared with caution. For telavancin we provided data for the administration dose of $10 \mathrm{mg} / \mathrm{kg}$ $\mathrm{BW}$, which is the recommended dose for patients with a creatinine clearance $\left(\mathrm{CL}_{\mathrm{CR}}\right)$ above $50 \mathrm{~mL} / \mathrm{min}$ and for the dose of $7.5 \mathrm{mg} / \mathrm{kg}$, which is the recommended dose for a $\mathrm{CL}_{\mathrm{CR}}$ from 30 to $50 \mathrm{~mL} / \mathrm{min}$.

The ratio of $\mathrm{AUC}_{24}$ of drug in tissue to the $\mathrm{AUC}_{24}$ of drug in plasma (AUC ratio) serves as an index for tissue penetration of the respective drug. In this regard, it is important to differentiate whether the unbound fraction of the drug or the total drug concentration was used to calculate the AUC ratio. AUC ratios, which are not derived from the same drug fractions, are only comparable to a limited extent. In Table 5 the underlying drug fractions for the calculation of the AUC ratios are indicated.

Among the glycopeptides vancomycin exhibits the greatest penetration into blister fluid, with an AUC ratio of $80 \%$ in patients with lower limb infections [45]. Teicoplanin shows the second greatest AUC ratio with $77 \%$, followed by dalbavancin with $60 \%$, telavancin with $40 \%$, and oritavancin with merely $19 \%$ [36, 46-48]. However, as indicated, data from interstitial space fluid might be considered more relevant, and telavancin achieves near complete plasma to tissue equilibration between the free fraction in plasma and the concentration in interstitial space fluid (unbound fraction; values obtained by microdialysis) of muscle $(0.93 \pm 0.60)$. In contrast to muscle tissue (values obtained by microdialysis) for ELF (values obtained by bronchoalveolar lavage) the free fraction of telavancin is unknown. Therefore, direct comparison of the tissue to plasma ratio of muscle and ELF is not possible. When concentrations of telavancin in ELF are compared to total plasma, AUC ratios of 0.093 are found [48-50]. A comparison of the penetration of glycopeptides into lung tissue cannot be performed, because currently available data on the pharmacokinetic in lung tissue of healthy subjects are limited to telavancin.

\section{Influence of Organ Impairment and Drug-Drug Interactions}

In Table 6 we present data from two studies that investigated the influence of renal impairment on the pharmacokinetics of telavancin. In the first study, patients with 


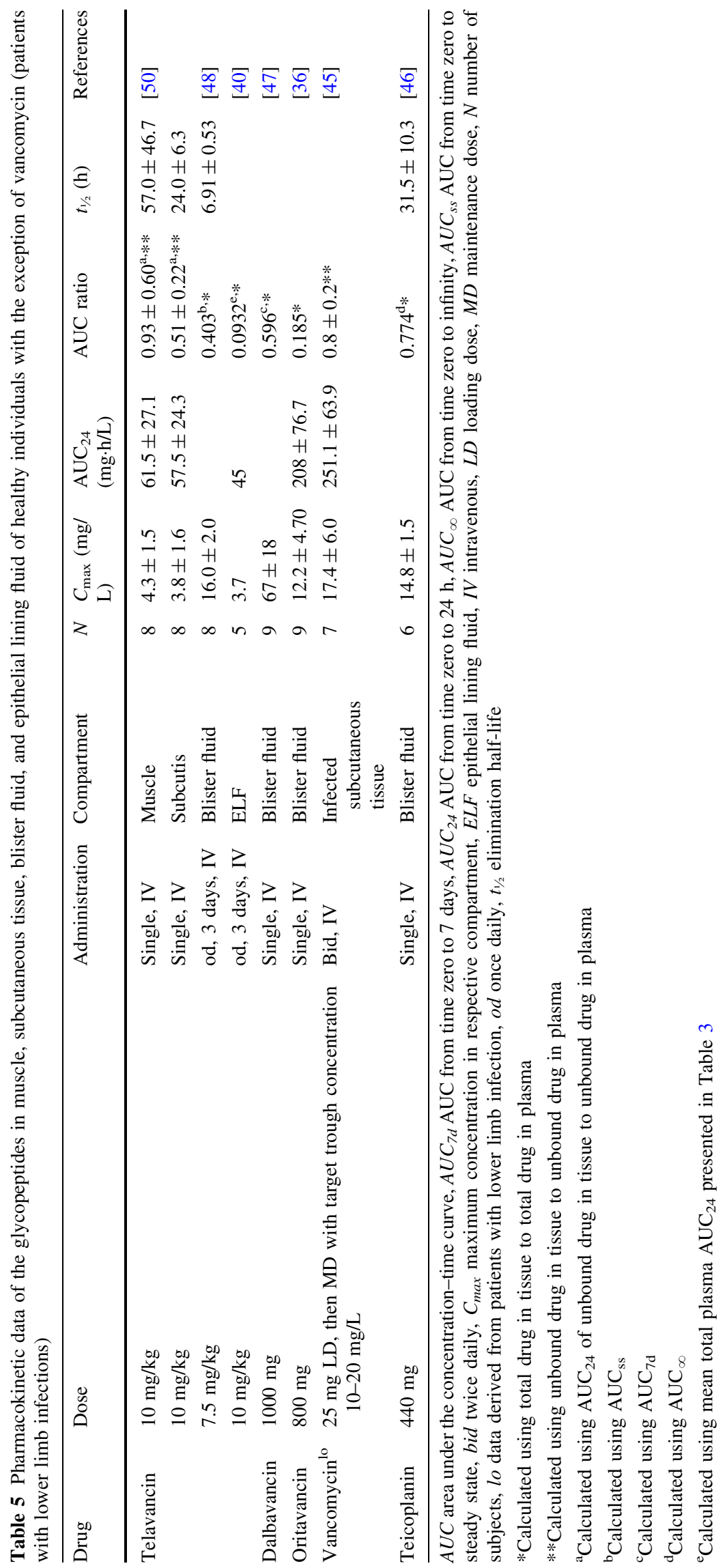




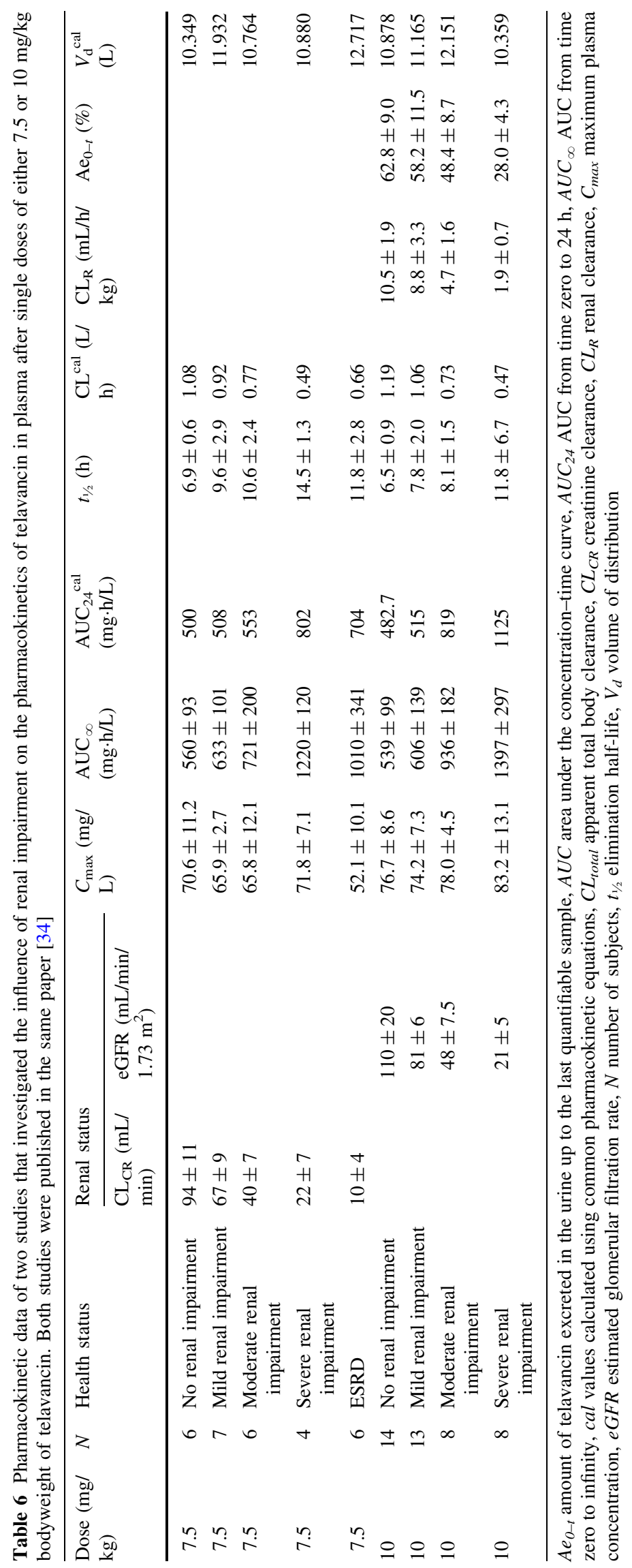


various degrees of renal impairment received $10 \mathrm{mg} / \mathrm{kg}$ BW of telavancin and in the second study the patients received $7.5 \mathrm{mg} / \mathrm{kg} \mathrm{BW}$. In both studies, patients were grouped by their $\mathrm{CL}_{\mathrm{CR}}$ as patients with no renal impairment, mild renal impairment, moderate renal impairment, severe renal impairment, and end-stage renal disease (ESRD) receiving hemodialysis (only in the second study). In the study with $10 \mathrm{mg} / \mathrm{kg} \mathrm{BW}$ as the administered dose, the renal clearance $\left(\mathrm{CL}_{\mathrm{R}}\right)$ and the total clearance of telavancin $\left(\mathrm{CL}_{\text {total }}\right)$ were falling in accordance with the decreasing renal function [34]; i.e., the $\mathrm{CL}_{\mathrm{R}}$ and $\mathrm{CL}_{\text {total }}$ were decreasing from $10.5 \pm 1.9 \mathrm{~mL} / \mathrm{h} / \mathrm{kg}$ and $1.19 \mathrm{~L} / \mathrm{h}$ in patients with no renal impairment to $1.9 \pm 0.7 \mathrm{~mL} / \mathrm{h} / \mathrm{kg}$ and $0.47 \mathrm{~L} / \mathrm{h}$ in patients with severe renal impairment. Correspondingly, the $\mathrm{AUC}_{\infty}, \mathrm{AUC}_{24}$, and $t_{1 / 2}$ were rising markedly with decreasing degrees of renal function. In line with this observation the summary of product characteristics (SmPC) recommends a modification of the administered dose for patients with a $\mathrm{CL}_{\mathrm{CR}}$ of $30-50 \mathrm{~mL} / \mathrm{min}$ to $7.5 \mathrm{mg} /$ $\mathrm{kg} \mathrm{BW}$ and does not indicate the administration for patients with a $\mathrm{CL}_{\mathrm{CR}}<30 \mathrm{~mL} / \mathrm{min}$.

In the second study the pharmacokinetic parameters after a dose of $7.5 \mathrm{mg} / \mathrm{kg}$ BW of telavancin were studied [34]. Here again, in patients with decreasing renal function the $\mathrm{AUC}_{\infty}$ and $t_{1 / 2}$ were rising accordingly, from $560 \pm 93 \mathrm{mg} \cdot \mathrm{h} / \mathrm{L}$ and $6.9 \pm 0.6 \mathrm{~h}$ in patients with no renal impairment to $1220 \pm 120 \mathrm{mg} \cdot \mathrm{h} / \mathrm{L}$ and $14.5 \pm 1.3 \mathrm{~h}$ in patients with severe renal impairment, whereas the $\mathrm{CL}_{\text {total }}$ was falling from 1.08 to $0.49 \mathrm{~L} / \mathrm{h}$. Indeed, $7.5 \mathrm{mg} / \mathrm{kg} \mathrm{BW}$ achieved exposure levels in patients with up to moderate renal impairment that were comparable to the standard dose in subjects with normal kidney function, whereas for more severe forms $7.5 \mathrm{mg} / \mathrm{kg}$ results in overexposure. Moreover, a number of studies demonstrated that telavancin leads to increases in serum creatinine and exhibits a potential for nephrotoxicity [51-53].

There are only a limited number of studies available that investigated the interactions of telavancin with other antibiotics. In a study by Wong et al., pharmacokinetic interactions between telavancin $(10 \mathrm{mg} / \mathrm{kg} \mathrm{BW}$, single dose) and aztreonam ( $2 \mathrm{~g}$, single dose) or piperacillin/tazobactam ( $4.5 \mathrm{~g}$, single dose) were investigated. The authors administered either combination to healthy participants and compared the resulting pharmacokinetic parameters with the pharmacokinetic parameters after administration of telavancin alone. There were no significant changes in the pharmacokinetic parameters after coadministration of telavancin with either aztreonam or piperacillin/tazobactam [54].

Another study investigated the effect of telavancin $(10 \mathrm{mg} / \mathrm{kg} \mathrm{BW})$ on the pharmacokinetics of midazolam. The rationale behind this study was to evaluate the influence of telavancin on hepatic cytochrome P450 (CYP) 3A activity by using midazolam as a CYP3A probe substrate. The authors demonstrated that telavancin does not alter the pharmacokinetics of midazolam to a clinically relevant extent. Therefore, a clinically relevant influence of telavancin on the activity of CYP3A is not expected by the authors [55]. Other drug-drug interactions of telavancin based on the CYP450 enzyme systems are not described. In accordance with this finding, the SmPC does not recommend a dose adjustment for patients with mild to moderate hepatic impairment (Child-Pugh class B). For patients with severe hepatic impairment (Child-Pugh class C), the SmPC states that caution should be exercised, since there are no data available for this patient collective.

\section{Pharmacodynamics}

\subsection{Pharmacodynamic Parameters}

\subsubsection{Minimal Inhibitory Concentrations}

Tables 7 and 8 show the MIC values of telavancin and vancomycin against clinically relevant Gram -positive pathogens. The data are derived from two in vitro studies that investigated the MIC of various antibiotic agents against a wide number of clinical isolates from various clinical settings. The susceptibility testing method for telavancin has been revised in 2014 by the Clinical and Laboratory Standards Institute (CLSI) to increase solubility and minimize adherence to plastic surfaces. The studies we included in our review used the revised testing methods. However, it has to be emphasized that earlier studies potentially underestimate the in vitro activity of telavancin, since the old testing method results in considerably higher MICs [56].

For the interpretation of the respective MICs of telavancin, the revised breakpoints as approved by the FDA were used. Since there are no defined interpretive breakpoints for telavancin against $S$. epidermidis and $S$. pneumoniae, statements about resistance cannot be made for these bacteria. The MICs of vancomycin were interpreted using the breakpoints published by the CLSI. For completeness, we also give the susceptibility breakpoints published by the European Committee on Antimicrobial Susceptibility Testing (EUCAST; http://www.eucast.org) in Table 9.

The first study performed susceptibility testing on 12,346 Gram-positive clinical isolates, which were collected from 90 study sites worldwide. In this study telavancin was found to be 16- to 32 -fold more active against MRSA and 6- to 16-fold more active against vancomycinsusceptible E. faecalis than vancomycin. Furthermore, telavancin showed 64-fold lower MIC required to inhibit 
Table 7 Minimal inhibitory concentration of telavancin and vancomycin against clinically relevant bacteria from a worldwide collection of clinical isolates (data modified from Mendes et al. [57])

\begin{tabular}{|c|c|c|c|c|c|}
\hline Organism (number tested)/antimicrobial agent & $\mathrm{MIC}_{50}(\mu \mathrm{g} / \mathrm{mL})$ & $\mathrm{MIC}_{90}(\mu \mathrm{g} / \mathrm{mL})$ & $\%$ Susceptible $^{\mathrm{a}}$ & $\%$ Intermediate & $\%$ Resistant \\
\hline \multicolumn{6}{|l|}{ Staphylococcus aureus, MSSA (4230) } \\
\hline Telavancin & 0.03 & 0.06 & 100 & 0 & 0 \\
\hline \multicolumn{6}{|l|}{ S. aureus, MRSA (2613) } \\
\hline Telavancin & 0.03 & 0.06 & 100 & 0 & 0 \\
\hline Vancomycin & 1 & 1 & 100 & 0 & 0 \\
\hline \multicolumn{6}{|l|}{ Enterococcus faecalis (702) } \\
\hline Telavancin & 0.12 & 0.12 & 98.4 & & \\
\hline Vancomycin & 1 & 2 & 98.4 & 0.2 & 1.4 \\
\hline \multicolumn{6}{|l|}{ E. faecium, vancomycin susceptible (228) } \\
\hline Telavancin & $\leq 0.015$ & 0.03 & & & \\
\hline Vancomycin & 1 & 1 & 100 & 0 & 0 \\
\hline \multicolumn{6}{|l|}{ S. pneumoniae (1878) } \\
\hline Telavancin & $\leq 0.015$ & $\leq 0.015$ & & & \\
\hline Vancomycin & 0.25 & 0.5 & 100 & 0 & 0 \\
\hline
\end{tabular}

CLSI Clinical and Laboratory Standards Institute, MIC minimal inhibitory concentration, $M I C_{50}$ MIC required to inhibit growth of $50 \%$ of organisms, $M I C_{90}$ MIC required to inhibit growth of $90 \%$ of organisms, MRSA methicillin-resistant S. aureus, MSSA methicillin-sensitive S. aureus

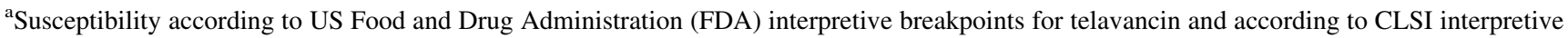
breakpoints for vancomycin

growth of $50 \%$ of organisms $\left(\mathrm{MIC}_{50}\right)$ values and 32 -fold lower MIC required to inhibit growth of $90 \%$ of organisms $\left(\mathrm{MIC}_{90}\right)$ values against vancomycin-susceptible $E$. faecium and 16- to 32-fold lower $\mathrm{MIC}_{50}$ and $\mathrm{MIC}_{90}$ values against S. pneumoniae than vancomycin [57].

For the second study, 33,433 clinical isolates were collected from 2007 to 2013 from Canadian hospitals and tested for their antimicrobial susceptibility. Telavancin was 16-fold more active than vancomycin against methicillin-sensitive $S$. aureus (MSSA) and MRSA strains and almost all the strains were sensitive to telavancin. The median MIC value of telavancin against hVISA and VISA was 16-fold lower than the median MIC of vancomycin. However, $10 \%$ of the hVISA isolates and $63.6 \%$ of the VISA isolates demonstrated resistance against telavancin. All of the seven clinical VRSA isolates were resistant to telavancin and vancomycin, but the median MIC of telavancin was 64-fold lower. Compared with vancomycin, telavancin showed 16-fold lower $\mathrm{MIC}_{50}$ and $\mathrm{MIC}_{90}$ values against S. epidermidis, regardless of methicillin susceptibility [58, 59].

Sweeney et al. [60] investigated the antimicrobial activity of telavancin, dalbavancin, oritavancin, and vancomycin against clinical $S$. aureus isolates, including MRSA. They evaluated the MIC of the antimicrobial agents against 15 MRSA and 12 MSSA strains. As measured by the $\mathrm{MIC}_{50 / 90}$, the lipoglycopeptides showed very similar antimicrobial activity, with dalbavancin being the most potent of the tested agents. Compared with vancomycin, they showed 8- to 32-fold lower MIC values against MSSA and MRSA strains [60]. The data from the study are displayed in Table 10.

These data demonstrate that telavancin exerts excellent in vitro activity against the tested bacteria. Furthermore, the $\mathrm{MIC}_{90}$ values of telavancin were at least 16-fold lower against all the tested organisms than those of vancomycin.

An innovative tool to discriminate wild-type organisms from organisms with resistance mechanisms, the epidemiological cut-off value (ECOFF) has been introduced to clinical microbiology in recent years. However, no ECOFF values have been defined for telavancin yet. Therefore, we are only giving the wild-type distributions of telavancin for the relevant organisms according to EUCAST in Table 11.

\subsubsection{Pharmacokinetic/Pharmacodynamic Index}

Telavancin exerts rapid concentration-dependent bactericidal activity in vitro against Gram-positive bacteria [61]. In the mouse neutropenic thigh model, i.e., the model that is most frequently used to determine pharmacokinetic/pharmacodynamic relationships of new antibiotics in vivo, the $\mathrm{AUC}_{24}$ divided by the MIC ( $\mathrm{AUC}_{24} / \mathrm{MIC}$ ratio) has been demonstrated to be the best pharmacokinetic/pharmacodynamic index to predict the antimicrobial efficacy of telavancin [62].

Dalbavancin and oritavancin have also been shown to exert concentration-dependent antimicrobial activity against Gram-positive organisms, whereas vancomycin exhibits time-dependent antimicrobial activity [63-66]. Teicoplanin exerts concentration-dependent killing against 
Table 8 Minimal inhibitory concentration of telavancin and vancomycin against clinically relevant bacteria isolated from Canadian hospitals (data modified from Zhanel et al. [58] and Nichol et al. [59])

\begin{tabular}{|c|c|c|c|c|c|}
\hline Organism (number tested)/antimicrobial agent & $\mathrm{MIC}_{50}(\mu \mathrm{g} / \mathrm{mL})$ & $\mathrm{MIC}_{90}(\mu \mathrm{g} / \mathrm{mL})$ & $\%$ Susceptible $^{\mathrm{a}}$ & $\%$ Intermediate & $\%$ Resistant \\
\hline \multicolumn{6}{|l|}{ Staphylococcus aureus, MSSA (4734) } \\
\hline Telavancin & 0.06 & 0.06 & 99.7 & 0 & 0.3 \\
\hline Vancomycin & 1 & 1 & 100 & 0 & 0 \\
\hline \multicolumn{6}{|l|}{ S. aureus, MRSA (1391) } \\
\hline Telavancin & 0.06 & 0.06 & 100 & 0 & 0 \\
\hline Vancomycin & 1 & 1 & 99.9 & 0.1 & 0 \\
\hline \multicolumn{6}{|l|}{ S. aureus, HA-MRSA (868) } \\
\hline Telavancin & 0.06 & 0.06 & 100 & 0 & 0 \\
\hline Vancomycin & 1 & 1 & 99.9 & 0.1 & 0 \\
\hline \multicolumn{6}{|l|}{ S. aureus, CA-MRSA (366) } \\
\hline Telavancin & 0.06 & 0.06 & 100 & 0 & 0 \\
\hline Vancomycin & 1 & 1 & 100 & 0 & 0 \\
\hline \multicolumn{6}{|l|}{ S. aureus, hVISA $(10)^{\mathrm{c}}$} \\
\hline Telavancin & $0.12^{\mathrm{b}}$ & & 90 & 0 & 10 \\
\hline Vancomycin & $2^{\mathrm{b}}$ & & 100 & 0 & 0 \\
\hline \multicolumn{6}{|l|}{ S. aureus, VISA $(11)^{\mathrm{d}}$} \\
\hline Telavancin & $0.25^{\mathrm{b}}$ & & 36.4 & 0 & 63.6 \\
\hline Vancomycin & $2^{\mathrm{b}}$ & & 81.8 & 18.2 & 0 \\
\hline \multicolumn{6}{|l|}{ S. aureus, VRSA (7) ${ }^{\mathrm{d}}$} \\
\hline Telavancin & $0.5^{\mathrm{b}}$ & & 0 & 0 & 100 \\
\hline Vancomycin & $32^{\mathrm{b}}$ & & 0 & 0 & 100 \\
\hline \multicolumn{6}{|l|}{ S. epidermidis, MSSE (533) } \\
\hline Telavancin & 0.06 & 0.12 & & & \\
\hline Vancomycin & 1 & 2 & 100 & 0 & 0 \\
\hline \multicolumn{6}{|l|}{ S. epidermidis, MRSE (97) } \\
\hline Telavancin & $0.06^{\mathrm{b}}$ & & & & \\
\hline Vancomycin & 1 & 2 & 100 & 0 & 0 \\
\hline \multicolumn{6}{|l|}{ S. pneumoniae (1931) } \\
\hline Telavancin & 0.008 & 0.015 & & & \\
\hline Vancomycin & $\leq 0.25$ & 0.25 & 100 & 0 & 0 \\
\hline
\end{tabular}

CA-MRSA community-acquired MRSA, CLSI Clinical and Laboratory Standards Institute, HA-MRSA hospital-acquired MRSA, hVISA heteroresistant vancomycin-intermediate $S$. aureus, $M I C$ minimal inhibitory concentration, $M I C_{50}$ MIC required to inhibit growth of $50 \%$ of organisms, $M I C_{90}$ MIC required to inhibit growth of $90 \%$ of organisms, MRSA methicillin-resistant $S$. aureus, MRSE methicillin-resistant $S$. epidermidis, MSSA methicillin-sensitive S. aureus, MSSE methicillin-sensitive S. epidermidis, VISA vancomycin-intermediate $S$. aureus, VRSA vancomycin-resistant $S$. aureus

${ }^{a}$ Susceptibility according to FDA interpretive breakpoints for telavancin and according to CLSI interpretive breakpoints for vancomycin

${ }^{\mathrm{b}}$ Median MIC value

${ }^{\mathrm{c}}$ Organisms collected as part of the CANWARD study [58]

${ }^{\mathrm{d} O r g a n i s m s ~ i d e n t i f i e d ~ a r e ~ p a r t ~ o f ~ t h e ~ N e t w o r k ~ o n ~ A n t i m i c r o b i a l ~ R e s i s t a n c e ~ i n ~ S . ~ a u r e u s ~(N A R S A) ~ r e p o s i t o r y ~}$

S. epidermidis. Controversial data exist regarding the relevant pharmacokinetic/pharmacodynamic index of teicoplanin against $S$. aureus. Odenholt et al. [67] investigated the mode of action of teicoplanin against $S$. aureus in a time-kill experiment with different static concentrations and were able to show a slight concentration-dependent killing after $12 \mathrm{~h}$ of $1-1.5$ colony-forming units (cfu)/mL. This finding is in contrast to several studies which found that there is a maximum effective concentration of teicoplanin and that concentrations above this value do not correlate with increased killing activity [68-70].

\subsection{Pharmacokinetics/Pharmacodynamics in Plasma}

Odenholt et al. [71] employed an in vitro pharmacokinetic model to investigate the relationship between $\mathrm{AUC}_{24} / \mathrm{MIC}$ and the extent of bacterial killing of telavancin. They 
Table 9 Minimal inhibitory concentration (MIC) breakpoints for the glycopeptides against the relevant bacteria as defined by the European Committee on Antimicrobial Susceptibility Testing (EUCAST). The first MIC value represents the susceptibility breakpoint, the second value represents the resistance breakpoint

\begin{tabular}{|c|c|c|c|c|c|}
\hline Organism & Telavancin & Dalbavancin & Oritavancin & Vancomycin & Teicoplanin \\
\hline Staphylococcus aureus & ND & $\leq 0.125 />0.125$ & $\leq 0.125 />0.125$ & $\leq 2 />2$ & $\leq 2 />2$ \\
\hline MRSA & $\leq 0.125$ & ND & ND & ND & ND \\
\hline S. epidermidis & ND & $\leq 0.125 />0.125$ & ND & $\leq 4 />4$ & $\leq 4 />4$ \\
\hline S. pneumoniae & IE & $\mathrm{IE}$ & IE & $\leq 2 />2$ & $\leq 2 />2$ \\
\hline Enterococcus faecalis & IE & $\mathrm{IE}$ & IE & $\leq 4 />4$ & $\leq 2 />2$ \\
\hline E. faecium & IE & $\mathrm{IE}$ & IE & $\leq 4 />4$ & $\leq 2 />2$ \\
\hline
\end{tabular}

$I E$ insufficient evidence, MRSA methicillin-resistant $S$. aureus, $N D$ not done

Table 10 MIC of the lipoglycopeptides and vancomycin against 12 methicillin-sensitive Staphylococcus aureus and 15 methicillin-resistant $S$. aureus strains (modified from Sweeney et al. [60])

\begin{tabular}{|c|c|c|c|c|c|}
\hline Organism (number tested)/antimicrobial agent & $\mathrm{MIC}_{50}(\mu \mathrm{g} / \mathrm{mL})$ & $\mathrm{MIC}_{90}(\mu \mathrm{g} / \mathrm{mL})$ & $\%$ Susceptible $^{a}$ & $\%$ Intermediate & \% Resistant \\
\hline \multicolumn{6}{|l|}{ Staphylococcus aureus, MSSA (12) } \\
\hline Telavancin & 0.06 & 0.06 & 100 & 0 & 0 \\
\hline Dalbavancin & 0.03 & 0.03 & 100 & 0 & 0 \\
\hline Oritavancin & 0.03 & 0.12 & 100 & 0 & 0 \\
\hline Vancomycin & 0.5 & 1 & 100 & 0 & 0 \\
\hline \multicolumn{6}{|l|}{ S. aureus, MRSA (15) } \\
\hline Telavancin & 0.06 & 0.06 & 100 & 0 & 0 \\
\hline Dalbavancin & 0.03 & 0.06 & 100 & 0 & 0 \\
\hline Oritavancin & 0.06 & 0.12 & 100 & 0 & 0 \\
\hline Vancomycin & 1 & 1 & 100 & 0 & 0 \\
\hline
\end{tabular}

CLSI Clinical and Laboratory Standards Institute, $M I C$ minimal inhibitory concentration, $M I C_{50}$ MIC required to inhibit growth of $50 \%$ of organisms, $M I C_{90}$ MIC required to inhibit growth of $90 \%$ of organisms, MRSA methicillin-resistant S. aureus, MSSA methicillin-sensitive $S$. aureus

${ }^{a}$ Susceptibility according to US Food and Drug Administration (FDA) interpretive breakpoints for telavancin, dalbavancin, and oritavancin and according to CLSI interpretive breakpoints for vancomycin

demonstrated that a free $\mathrm{AUC}_{24} / \mathrm{MIC}\left(\mathrm{fAUC}_{24} / \mathrm{MIC}\right.$ ) ratio of 50 produces $>3-\log$ killing at $6-8 \mathrm{~h}$ against MSSA and MRSA and is the lowest $\mathrm{AUC}_{24} / \mathrm{MIC}$ ratio to detain bacterial regrowth after $24 \mathrm{~h}$. Maximum killing was obtained against the two strains at an $\mathrm{AUC}_{24} / \mathrm{MIC}$ ratio of 404 [71]. Another in vitro study found similar fAUC ${ }_{24} / \mathrm{MIC}_{90}$ targets for telavancin against $S$. aureus. MacGowan et al. [72] performed dose-ranging studies for telavancin against five vancomycin-susceptible $S$. aureus and three Enterococcus strains. The authors demonstrated that a bacteriostatic effect after $24 \mathrm{~h}$ can be achieved with mean $\mathrm{fAUC}_{24} / \mathrm{MIC}_{90}$ ratios of 43.1 and 15.1 for vancomycin-susceptible $S$. aureus and enterococci, respectively, and a 1-log-unit reduction in the viable counts with ratios of 50.0 and 40.1 for vancomycin-susceptible $S$. aureus and enterococci, respectively. Furthermore, the maximum bactericidal effect against vancomycin-susceptible $S$. aureus was achieved with a $\mathrm{fAUC}_{24} / \mathrm{MIC}_{90}$ ratio of $>150$ [72]. Employing an in vivo neutropenic murine thigh and murine lung infection model, Lepak et al. [73] further explored $\mathrm{AUC}_{24} / \mathrm{MIC}$ targets for telavancin and vancomycin against $S$. aureus strains, including MRSA. For telavancin they found that mean $\mathrm{fAUC}_{24} / \mathrm{MIC}$ values of 83.0 in the thigh model and 40.4 in the lung model were necessary to ensure bacterial stasis. Telavancin mean fAUC $_{24} / \mathrm{MIC}$ values of 215 and 76.4 were necessary for the thigh and lung models, respectively, to achieve killing of $1 \log \mathrm{cfu} / \mathrm{mL}$. For vancomycin the experiments showed very similar fAUC ${ }_{24} /$ MIC target ratios, with 77.9 and 45.3 for bacterial stasis and 282 and 113 for bacterial killing of $1 \log \mathrm{cfu} / \mathrm{mL}$ in the thigh and lung models, respectively [73]. These data indicate comparable pharmacokinetic/pharmacodynamic targets for telavancin and vancomycin, but also highlight the impact of the employed model and side of infection. With 


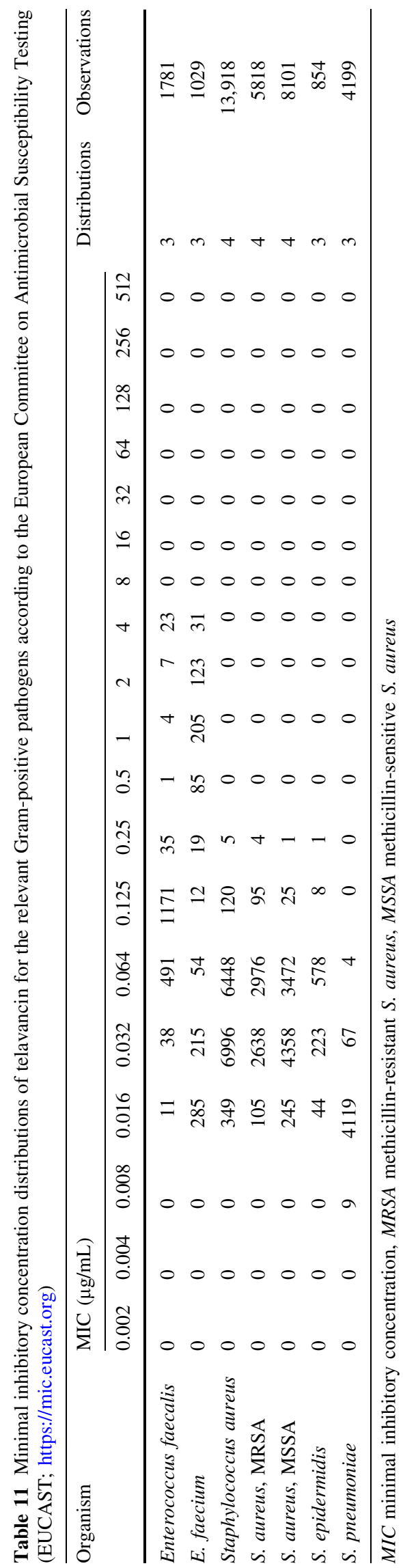

regard to animal pharmacokinetic/pharmacodynamic studies, it has to be kept in mind that protein binding in animals might be different to humans and is an important factor that influences pharmacokinetics and pharmacodynamics. In the study by Lepak et al. [73], the protein binding in mice was $96 \%$ compared to $90 \%$ in humans (according to the SmPC) for telavancin and $25 \%$ in mice compared to $30-55 \%$ in humans (according to the SmPC) for vancomycin. However, these fAUC/MIC calculations are considering unbound drug fractions and are therefore not affected by differences in protein binding.

For Table 12 we calculated the unbound $\mathrm{AUC}_{24}$ with the use of the protein binding as indicated in the SmPC of the respective drug, and the total $\mathrm{AUC}_{24}$ as displayed in Table 3. We then calculated the ratio of the $\mathrm{AUC}_{24}$ of unbound plasma concentrations to the $\mathrm{MIC}_{90}$ (fAUC ${ }_{24} /$ $\mathrm{MIC}_{90}$ ). For the $\mathrm{MIC}_{90}$ we utilized the previously illustrated values (Tables 7, 8, 10). The focus of our review lies on telavancin, and therefore we selected studies that investigated the MIC of telavancin and, if possible, included other glycopeptides. Because it is not legitimate to directly compare MIC values of a certain pathogen from different studies, we could not provide comparative values for dalbavancin and oritavancin against bacteria other than S. aureus.

At a dose of $10 \mathrm{mg} / \mathrm{kg} \mathrm{BW}$, the calculated $\mathrm{AUC}_{24} /$ $\mathrm{MIC}_{90}$ ratio of telavancin is 805 against clinical MSSA and MRSA isolates. Assuming the aforementioned $\mathrm{AUC}_{24} /$ MIC targets, telavancin concentrations would therefore be sufficient to achieve maximum efficacy against the tested $S$. aureus strains. To date, $\mathrm{AUC}_{24} / \mathrm{MIC}$ target values for telavancin against $S$. epidermidis and $S$. pneumoniae have not been published. For analysis, we are therefore applying the target ratio range of 150-404 for maximum killing against $S$. aureus to $S$. epidermidis. Using this target ratio, the activity of telavancin would be sufficient against methicillin-sensitive S. epidermidis (ratio of 403) to achieve maximum killing. However, this predication has to be interpreted with caution. Since $S$. pneumoniae and enterococci show very different pharmacodynamic properties to $S$. aureus, it is not legitimate apply the target ratios of $S$. aureus to them. The $\mathrm{AUC}_{24} / \mathrm{MIC}$ target value for 1-log kill of enterococci was exceeded by far for telavancin against E. faecalis and E. faecium. A target value for maximum killing against enterococci has not yet been published.

The previously mentioned study of Lepak et al. [73] provided an $\mathrm{AUC}_{24} / \mathrm{MIC}$ threshold of 400 for vancomycin, above which bacterial killing of $S$. aureus did not increase. Several clinical studies demonstrated $\mathrm{AUC}_{24} / \mathrm{MIC}$ target ratios in the same range and a consensus guideline has been published that defines a $\mathrm{AUC}_{24} / \mathrm{MIC}$ target ratio of $\geq 400$ as being best correlated with clinical 
Table 12 Ratio of the area under the plasma concentration-time curve from 0 to $24 \mathrm{~h}\left(\mathrm{AUC}_{24}\right)$ of unbound plasma concentrations to minimal inhibitory concentration required to inhibit growth of $90 \%$ of organisms $\left(\mathrm{MIC}_{90}\right)$ for relevant Gram-positive pathogens

\begin{tabular}{|c|c|c|c|c|c|c|c|c|c|}
\hline & Dose & $\begin{array}{l}\mathrm{AUC}_{24} \\
(\mathrm{mg} \cdot \mathrm{h} / \\
\mathrm{L})\end{array}$ & $\begin{array}{l}\text { Unbound } \\
\text { AUC }_{24} \\
(\mathrm{mg} \cdot \mathrm{h} / \mathrm{L})\end{array}$ & $\begin{array}{l}\text { Staphylococcus } \\
\text { aureus, MSSA } \\
{[60]}\end{array}$ & $\begin{array}{l}S . \\
\text { aureus, } \\
\text { MRSA } \\
{[60]}\end{array}$ & $\begin{array}{l}\text { S. } \\
\text { epidermidis, } \\
M S S E \\
{[58,59]}\end{array}$ & $\begin{array}{l}S . \\
\text { pneumoniae } \\
{[57]}\end{array}$ & $\begin{array}{l}\text { Enterococcus } \\
\text { faecalis [57] }\end{array}$ & $\begin{array}{l}E . \\
\text { faecium, } \\
\text { VSE [57] }\end{array}$ \\
\hline Telavancin & $10 \mathrm{mg} / \mathrm{kg}$ & 482.7 & 48.3 & 805 & 805 & 403 & 3220 & 403 & 1610 \\
\hline Dalbavancin & $1000 \mathrm{mg}$ & 3342.25 & 233.96 & 7799 & 3899 & & & & \\
\hline Oritavancin & $800 \mathrm{mg}$ & 1111 & 166.7 & 1389 & 1389 & & & & \\
\hline Vancomycin & $\begin{array}{l}25 \mathrm{LD} \text {, then } \mathrm{MD} \\
\text { with target } \\
\text { trough } \\
\text { concentration } \\
10-20 \mathrm{mg} / \mathrm{L}\end{array}$ & 442.6 & 265.6 & 266 & 266 & 133 & 1062 & 133 & 266 \\
\hline
\end{tabular}

$A U C$ area under the concentration-time curve, $A U C_{24}$ AUC from time zero to $24 \mathrm{~h}, L D$ loading dose, $M D$ maintenance dose, $M R S A$ methicillinresistant $S$. aureus, MSSA methicillin-sensitive S. aureus, MSSE methicillin-sensitive S. epidermidis, VSE vancomycin-sensitive enterococcus

effectiveness against S. aureus [74-77]. However, this ratio is derived from the total $\mathrm{AUC}_{24}$ and, considering a protein binding of vancomycin of $40 \%$, the calculated fAUC $_{24} / \mathrm{MIC}$ target ratio would be $\geq 240$. This ratio is achieved by vancomycin in our calculations (Table 12). Unfortunately, no target ratios for vancomycin against $S$. epidermidis, S. pneumoniae, and enterococci have been established yet. For the purpose of comparison, we therefore applied the fAUC $24 / \mathrm{MIC}$ target ratio of $\geq 240$ to $S$. epidermidis. Using this value, vancomycin showed insufficient antimicrobial activity against $S$. epidermidis.

The fAUC ${ }_{24} / \mathrm{MIC}$ target ratio of $100-300$ against $S$. aureus has been demonstrated for dalbavancin [63]. Dalbavancin exceeds this ratio widely for the indicated dose. No AUC/MIC target values have been established for oritavancin, but the relatively high fAUC $_{24} / \mathrm{MIC}$ ratio of 1389 demonstrated in our calculations appears to be adequate for the treatment of $S$. aureus infections.

It should be noted that the $\mathrm{fAUC}_{24} / \mathrm{MIC}$ values we calculated are based on the $\mathrm{AUC}_{24}$ after single doses of the examined substances, and in the clinical setting with multiple dosing even higher ratios could be reasonably expected.

\subsection{Combination Therapy}

Leonard et al. [78] employed in vitro time-kill synergy studies and a pharmacokinetic/pharmacodynamic infection model to evaluate the synergistic effect of telavancin combined with nafcillin, imipenem, or gentamicin. The time-kill analysis showed high rates of synergy between telavancin and all of the tested agents. In the pharmacokinetic/pharmacodynamic models, the authors were able to reproduce these synergistic effects against two MSSA, two MRSA, and two hVISA strains [78]. Tängdén et al. [79] performed time-kill experiments and found no synergistic effect of telavancin in combination with colistin against Verona imipinemase (VIM)-producing Klebsiella pneumonia strains.

In a synergy time-kill study by Lin et al. [80], the synergistic activity of telavancin in combination with various antibiotics was tested against different MRSA strains. After $24 \mathrm{~h}$ of incubation the combination of a subinhibitory concentration of telavancin with subinhibitory concentrations of gentamicin, ceftriaxone, meropenem, or rifampin (rifampicin) showed synergy rates of $90,88,65$, and $65 \%$, respectively [80]. This observation is backed up by another in vitro study by Leonard et al. [81] where bacterial killing of telavancin was significantly enhanced in combination with gentamicin against heteroresistant glycopeptide-intermediate $S$. aureus (hGISA), glycopeptide-intermediate S. aureus (GISA), and MSSA. Finally, an in vitro pharmacokinetic/pharmacodynamic study by Yim et al. [82] investigated possible antagonism between telavancin and aztreonam or piperacillin/tazobactam against Pseudomonas aeruginosa, Escherichia coli, and MRSA in simulated reduced renal function conditions. In their model, the combination of telavancin with either of the other two antibiotics did not lead do any antagonistic effects [82].

\section{Discussion}

The pharmacokinetic characteristics of the members of the group of glycopeptides show considerable differences. With regard to the single-dose pharmacokinetics, telavancin takes an intermediate position among the 
glycopeptides. In contrast to the newer lipoglycopeptides, telavancin demonstrates a relatively short $t_{1 / 2}$ and rapid total clearance, which warrants once-daily dosing schemes. The multiple-dose pharmacokinetics of telavancin demonstrate only a slight accumulation compared with its single-dose pharmacokinetics, with an increase of the $t_{1 / 2}$ of less than $15 \%$. The other glycopeptides show much greater differences, with increases in the $t_{1 / 2}$ of $55-260 \%$ for the investigated dosing patterns.

Our analysis of the pharmacokinetics in relevant tissues set out the potential of telavancin for the treatment of soft tissue infections, especially when considering the concentrations that were determined in interstitial space fluid (using microdialysis). Telavancin shows a high plasma protein binding of $90 \%$ according to the SmPC and its $V_{\mathrm{d}}$ is almost identical to dalbavancin but markedly lower than the value for vancomycin and teicoplanin. However, telavancin shows excellent soft tissue penetration (concentration values obtained using microdialysis), as indicated by the unbound AUC tissue to plasma ratio. The penetration of telavancin into ELF (concentration values obtained through bronchoalveolar lavage) as indicated by the AUC tissue to plasma ratio seems relatively low; however, total concentrations were used for this ratio and further studies using free drug concentrations are needed for a more exhaustive analysis.

Staphylococcus aureus is known to invade and survive inside eukaryotic cells, evading the immune system and causing chronic or recurrent infections. This ability of $S$. aureus is hypothesized to be one of the reasons for failures in the treatment of MRSA infections [83-87]. Among the investigated glycopeptides, oritavancin shows the greatest intracellular accumulation in macrophages and exhibits the most pronounced intracellular activity [88-92]. Telavancin also shows some uptake into macrophages and fibroblasts and even a moderate intracellular bactericidal activity, whereas vancomycin and teicoplanin only reach marginal intracellular concentrations [89, 93, 94].

Therapeutic drug monitoring is necessary for vancomycin because of the intrinsic inter-individual variability in the pharmacokinetics of the antibiotic as well as differing pharmacokinetics in patients with impaired renal function and obese patients. In order to minimize nephrotoxicity and development of resistance, this is usually performed by determination of trough concentrations that should be in the magnitude of 10-15 (sometimes up to 20) $\mu \mathrm{g} / \mathrm{mL}[74,95]$. In contrast to vancomycin, by decreasing the daily dose to $7.5 \mathrm{mg} / \mathrm{kg} \mathrm{BW}$, exposure levels of telavancin can be kept in a safe and effective range in patients with up to moderate renal impairment. Therefore, no therapeutic drug monitoring is necessary for telavancin according to the SmPC. However, the lack of a widely available assay to determine telavancin concentrations can also be considered a major disadvantage of the drug.

For telavancin, there are no studies investigating the exposure-toxicity relationship in humans. However, study data for vancomycin indicate a clear correlation between drug exposure measured in trough concentrations and nephrotoxicity. The authors of this study showed that with rising trough concentrations of vancomycin the odds ratio for nephrotoxicity also rises. At concentrations of $10-15 \mu \mathrm{g} / \mathrm{mL}$ the odds ratio was 3.65 compared with an odds ratio of 1 for concentrations of $0-10 \mu \mathrm{g} / \mathrm{mL}$. In contrast, at concentrations of $15-20 \mu \mathrm{g} / \mathrm{mL}$ the odds ratio was already 7.99 and at concentrations $>20 \mu \mathrm{g} / \mathrm{mL}$ it was as high as 45.3 [96].

When looking at the pharmacokinetic/pharmacodynamic data of telavancin and the other lipoglycopeptides, their noticeable potency against $S$. aureus, including MRSA, becomes apparent. The ratio of the $\mathrm{AUC}_{24}$ of unbound plasma concentrations to the $\mathrm{MIC}_{90}$ of $S$. aureus for all the lipoglycopeptides appears sufficiently high to achieve maximum killing. Furthermore, when applying the unbound $\mathrm{AUC}_{24} / \mathrm{MIC}$ target value of $S$. aureus to $S$. epidermidis, telavancin also achieves maximum antimicrobial efficacy. These findings highlight the potential of telavancin to treat infections caused by $S$. aureus, including MRSA and S. epidermidis. With regard to this, and considering the penetration into soft tissues as measured by the ratio of the AUC of drug in plasma to the AUC of drug in tissue, telavancin appears to be a promising antimicrobial agent to treat soft tissue infections caused by the aforementioned organisms. This also applies for dalbavancin with respect to soft tissue infections caused by $S$. aureus, including MRSA. However, further studies that investigate the penetration of dalbavancin and oritavancin into tissues using free drug fractions are required to provide a more accurate estimation of their tissue penetration in vivo.

Although the $\mathrm{AUC}_{24} / \mathrm{MIC}$ ratios of telavancin would suggest sufficient antimicrobial killing of $S$. aureus, one of the most frequently isolated bacteria in hospital-acquired pneumonia, the low penetration of telavancin into ELF as measured by total drug fractions demands further investigations [97].

In 2014 the CLSI revised the guidelines for broth microdilution susceptibility testing of telavancin. With regard to isolates with decreased susceptibility to vancomycin, using the revised CLSI guidelines telavancin shows greater potency against hVISA, VISA, and VRSA strains than vancomycin as measured by the MIC (Table 8) [59].

Four double-blind clinical phase III studies were conducted to evaluate the efficacy of telavancin for the treatment of cSSSIs and nosocomial pneumonia. The ATLAS (Assessment of Telavancin in Complicated Skin and Skin 
Structure Infections) trials investigated the clinical efficacy of telavancin compared with vancomycin for the treatment of complicated SSSIs caused by Gram-positive bacteria in a large study population $(n=1876)$. The authors demonstrated that telavancin is non-inferior to vancomycin [98]. The ATTAIN (Assessment of Telavancin for Treatment of Hospital-Acquired Pneumonia) trials were conducted to evaluate the efficacy of telavancin compared with vancomycin for the treatment of patients with HABP caused by Gram-positive bacteria. The analysis of the clinical data from 1503 patients showed non-inferiority of telavancin compared with vancomycin regarding clinical response rates [99]. Furthermore, a retrospective analysis of the data from the ATLAS and ATTAIN trials provides evidence that telavancin is comparable with vancomycin for the treatment of cSSSI or HABP with concurrent $S$. aureus bacteremia [100].

\section{Conclusion}

In summary, the pharmacokinetic and pharmacodynamic properties of telavancin make it an effective treatment option for soft tissue infections and possibly infections of the respiratory tract caused by Gram-positive organisms. Yet, because of its nephrotoxic potential, clinical use should be carefully balanced based on risk-benefit expectations compared with other available glycopeptides.

Acknowledgements Open access funding provided by Medical University of Vienna.

\section{Compliance with Ethical Standards}

Funding No sources of funding were used to assist with the preparation of this review.

Conflict of interest Dr. Zeitlinger and Dr. al Jalali have no conflicts of interest that are relevant to the content of this review.

Open Access This article is distributed under the terms of the Creative Commons Attribution-NonCommercial 4.0 International License (http://creativecommons.org/licenses/by-nc/4.0/), which permits any noncommercial use, distribution, and reproduction in any medium, provided you give appropriate credit to the original author(s) and the source, provide a link to the Creative Commons license, and indicate if changes were made.

\section{References}

1. Levine DP. Vancomycin: a history. Clin Infect Dis. 2006;42:S5-12.

2. Olearo F, Albrich WC, Vernaz N, Harbarth S, Kronenberg A, Swiss Centre For Antibiotic Resistance Anresis. Staphylococcus aureus and methicillin resistance in Switzerland: regional differences and trends from 2004 to 2014. Swiss Med Wkly. 2016;146:w14339.
3. Walter J, Noll I, Feig M, Weiss B, Claus H, Werner G, et al. Decline in the proportion of methicillin resistance among Staphylococcus aureus isolates from non-invasive samples and in outpatient settings, and changes in the co-resistance profiles: an analysis of data collected within the Antimicrobial Resistance Sur. BMC Infect Dis. 2017; 17:169.

4. Klevens RM, Edwards JR, Tenover FC, McDonald LC, Horan $\mathrm{T}$, Gaynes R. Changes in the epidemiology of methicillin-resistant Staphylococcus aureus in intensive care units in US hospitals, 1992-2003. Clin Infect Dis. 2006;42:389-91.

5. McDonald LC. Trends in antimicrobial resistance in health careassociated pathogens and effect on treatment. Clin Infect Dis. 2006;42:S65-71.

6. European Centre for Disease Prevention and Control (ECDC). Antimicrobial resistance surveillance in Europe 2015. Annual Report of the European Antimicrobial Resistance Surveillance Network (EARS-Net). Stockholm: ECDC; 2017.

7. Maree CL, Daum RS, Boyle-Vavra S, Matayoshi K, Miller LG. Community-associated methicillin-resistant Staphylococcus aureus isolates causing healthcare-associated infections. Emerg Infect Dis. 2007;13:236-42.

8. Fridkin SK, Hageman JC, Morrison M, Sanza LT, Como-Sabetti K, Jernigan JA, et al. Methicillin-resistant Staphylococcus aureus disease in three communities. $\mathrm{N}$ Engl $\mathrm{J}$ Med. 2005;352:1436-44

9. Zhang S, Sun X, Chang W, Dai Y, Ma X. Systematic review and meta-analysis of the epidemiology of vancomycin-intermediate and heterogeneous vancomycin-intermediate Staphylococcus aureus isolates. PLoS One. 2015;10:e136082.

10. Sievert DM, Rudrik JT, Patel JB, McDonald LC, Wilkins MJ, Hageman JC. Vancomycin-Resistant Staphylococcus aureus in the United States, 2002-2006. Clin Infect Dis. 2008;46:668-74.

11. From the Centers for Disease Control and Prevention. Nosocomial enterococci resistant to vancomycin-United States, 1989-1993. JAMA. 1993;270:1796.

12. Borghi A, Coronelli C, Faniuolo L, Allievi G, Pallanza R, Gallo GG. Teichomycins, new antibiotics from Actinoplanes teichomyceticus nov. sp. IV. Separation and characterization of the components of teichomycin (teicoplanin). J Antibiot (Tokyo). 1984;37:615-20.

13. Judice JK, Pace JL. Semi-synthetic glycopeptide antibacterials. Bioorg Med Chem Lett. 2003;13:4165-8.

14. Leadbetter MR, Adams SM, Bazzini B, et al. Hydrophobic vancomycin derivatives with improved ADME properties: discovery of telavancin (TD-6424). J Antibiot (Tokyo). 2004;57:326-36.

15. Wenzler E, Rodvold KA. Telavancin: the long and winding road from discovery to Food and Drug Administration approvals and future directions. Clin Infect Dis. 2015;61:S38-47.

16. Saravolatz LD, Stein GE. Oritavancin: a long-half-life lipoglycopeptide. Clin Infect Dis. 2015;61:627-32.

17. Dash RP, Babu RJ, Srinivas NR. Review of the pharmacokinetics of dalbavancin, a recently approved lipoglycopeptide antibiotic. Infect Dis (Lond). 2017;49(7):483-92. https://doi.org/ 10.1080/23744235.2017.1296968.

18. Higgins DL, Chang R, Debabov DV, Leung J, Wu T, Krause $\mathrm{KM}$, et al. Telavancin, a multifunctional lipoglycopeptide, disrupts both cell wall synthesis and cell membrane integrity in methicillin-resistant Staphylococcus aureus. Antimicrob Agents Chemother. 2005;49:1127-34.

19. Song Y, Lunde CS, Benton BM, Wilkinson BJ. Further insights into the mode of action of the lipoglycopeptide telavancin through global gene expression studies. Antimicrob Agents Chemother. 2012;56:3157-64.

20. Lebreton F, Depardieu F, Bourdon N, Fines-Guyon M, Berger P, Camiade $\mathrm{S}$, et al. D-Ala-D-Ser VanN-type transferable 
vancomycin resistance in Enterococcus faecium. Antimicrob Agents Chemother. 2011;55:4606-12.

21. Sun M, Wang Y, Chen Z, Zhu X, Tian L, Sun Z. The first report of the vanC $\mathrm{C}_{1}$ gene in Enterococcus faecium isolated from a human clinical specimen. Mem Inst Oswaldo Cruz. 2014;109:712-5.

22. Hill CM, Krause KM, Lewis SR, Blais J, Benton BM, Mammen $M$, et al. Specificity of induction of the vanA and vanB operons in vancomycin-resistant enterococci by telavancin. Antimicrob Agents Chemother. 2010;54:2814-8.

23. Dutka-Malen S, Courvalin P. Update on glycopeptide resistance in enterococci. Antimicrob Newsl. 1990;7:81-6.

24. Draghi DC, Benton BM, Krause KM, Thornsberry C, Pillar C, Sahm DF. Comparative surveillance study of telavancin activity against recently collected gram-positive clinical isolates from across the United States. Antimicrob Agents Chemother. 2008;52:2383-8.

25. Evers S, Courvalin P. Regulation of VanB-type vancomycin resistance gene expression by the $\operatorname{VanS}(\mathrm{B})-\operatorname{VanR}$ (B) twocomponent regulatory system in Enterococcus faecalis V583. J Bacteriol. 1996;178:1302-9.

26. Courvalin P. Genetics of glycopeptide resistance in Gram-positive pathogens. Int J Med Microbiol. 2005;294:479-86.

27. Praharaj I, Sujatha S, Parija SC. Phenotypic \& genotypic characterization of vancomycin resistant Enterococcus isolates from clinical specimens. Indian J Med Res. 2013;138:549-56.

28. Toye B, Shymanski J, Bobrowska M, Woods W, Ramotar K. Clinical and epidemiologic significance of enterococci intrinsically resistant to vancomycin (possessing the vanC genotype). J Clin Microbiol. 1997;35:3166-70.

29. Hölzel C, Bauer J, Stegherr E-M, Schwaiger K. Presence of the vancomycin resistance gene cluster vanC1, vanXYc, and vanT in Enterococcus casseliflavus. Microb Drug Resist. 2014;20:177-80.

30. Leclercq R, Dutka-Malen S, Duval J, Courvalin P. Vancomycin resistance gene vanC is specific to Enterococcus gallinarum. Antimicrob Agents Chemother. 1992;36:2005-8.

31. Zhu W, Clark NC, McDougal LK, Hageman J, McDonald LC, Patel JB. Vancomycin-resistant Staphylococcus aureus isolates associated with Inc18-Like vanA plasmids in Michigan. Antimicrob Agents Chemother. 2008;52:452-7.

32. Courvalin P. Vancomycin resistance in gram-positive cocci. Clin Infect Dis. 2006;42(Suppl 1):S25-34.

33. Leuthner KD, Cheung CM, Rybak MJ. Comparative activity of the new lipoglycopeptide telavancin in the presence and absence of serum against 50 glycopeptide non-susceptible staphylococci and three vancomycin-resistant Staphylococcus aureus. J Antimicrob Chemother. 2006;58:338-43.

34. Worboys PD, Wong SL, Barriere SL. Pharmacokinetics of intravenous telavancin in healthy subjects with varying degrees of renal impairment. Eur J Clin Pharmacol. 2015;71:707-14.

35. Scoble PJ, Owens RC, Puttagunta S, Yen M, Dunne MW. Pharmacokinetics, safety, and tolerability of a single 500-mg or 1000-mg intravenous dose of dalbavancin in healthy Japanese subjects. Clin Drug Investig. 2015;35:785-93.

36. Fetterly GJ, Ong CM, Bhavnani SM, Loutit JS, Porter SB, Morello LG, et al. Pharmacokinetics of oritavancin in plasma and skin blister fluid following administration of a 200-milligram dose for 3 days or a single 800-milligram dose. Antimicrob Agents Chemother. 2005;49:148-52.

37. Boeckh M, Lode H, Borner K, Hoffken G, Wagner J, Koeppe P. Pharmacokinetics and serum bactericidal activity of vancomycin alone and in combination with ceftazidime in healthy volunteers. Antimicrob Agents Chemother. 1988;32:92-5.

38. Verbist L, Tjandramaga B, Hendrickx B, Van Hecken A, Van Melle $\mathrm{P}$, Verbesselt $\mathrm{R}$, et al. In vitro activity and human pharmacokinetics of teicoplanin. Antimicrob Agents Chemother. 1984;26:881-6.

39. Shaw J-P, Cheong J, Goldberg MR, Kitt MM. Mass balance and pharmacokinetics of [14C]telavancin following intravenous administration to healthy male volunteers. Antimicrob Agents Chemother. 2010;54:3365-71.

40. Gotfried MH, Shaw JP, Benton BM, Krause KM, Goldberg MR, Kitt MM, et al. Intrapulmonary distribution of intravenous telavancin in healthy subjects and effect of pulmonary surfactant on in vitro activities of telavancin and other antibiotics. Antimicrob Agents Chemother. 2008;52:92-7.

41. Marbury T, Dowell JA, Seltzer E, Buckwalter M. Pharmacokinetics of dalbavancin in patients with renal or hepatic impairment. J Clin Pharmacol. 2009;49:465-76.

42. Thompson GA, Smithers JA, Kenny MT, Dulworth JK, Kulmala HK, Yuh L, et al. Pharmacokinetics of teicoplanin upon multiple dose intravenous administration to normal healthy male volunteers. Biopharm Drug Dispos. 1992;13:213-20.

43. Healy DP, Polk RE, Garson ML, Rock DT, Comstock TJ. Comparison of steady-state pharmacokinetics of two dosage regimens of vancomycin in normal volunteers. Antimicrob Agents Chemother. 1987;31:393-7.

44. Brunner M, Schmiedberger A, Schmid R, Jäger D, Piegler E, Eichler HG, et al. Direct assessment of peripheral pharmacokinetics in humans: comparison between cantharides blister fluid sampling, in vivo microdialysis and saliva sampling. Br J Clin Pharmacol. 1998;46:425-31.

45. Housman ST, Bhalodi AA, Shepard A, Nugent J, Nicolau DP. Vancomycin tissue pharmacokinetics in patients with lowerlimb infections via in vivo microdialysis. J Am Podiatr Med Assoc. 2015;105:381-8.

46. Wise R, Donovan IA, McNulty CAM, Waldron R, Andrews JM. Teicoplanin, its pharmacokinetics, blister and peritoneal fluid penetration. J Hosp Infect. 1986;7:47-55.

47. Nicolau DP, Sun HK, Seltzer E, Buckwalter M, Dowell JA. Pharmacokinetics of dalbavancin in plasma and skin blister fluid. J Antimicrob Chemother. 2007;60:681-4.

48. Sun HK, Duchin K, Nightingale CH, Shaw JP, Seroogy J, Nicolau DP. Tissue penetration of telavancin after intravenous administration in healthy subjects. Antimicrob Agents Chemother. 2006;50:788-90.

49. Lodise TP, Gotfried M, Barriere S, Drusano GL. Telavancin penetration into human epithelial lining fluid determined by population pharmacokinetic modeling and Monte Carlo simulation. Antimicrob Agents Chemother. 2008;52:2300-4.

50. Matzneller P, Österreicher Z, Reiter B, Lackner E, Stimpfl T, Zeitlinger M. Tissue pharmacokinetics of telavancin in healthy volunteers: a microdialysis study. J Antimicrob Chemother. 2016;71:3179-84.

51. Stryjewski ME, Chu VH, O'Riordan WD, et al. Telavancin versus standard therapy for treatment of complicated skin and skin structure infections caused by gram-positive bacteria: FAST 2 study. Antimicrob Agents Chemother. 2006;50:862-7.

52. Chuan J, Zhang Y, He X, Zhu Y, Zhong L, Yu D, et al. Systematic review and meta-analysis of the efficacy and safety of telavancin for treatment of infectious disease: are we clearer? Front Pharmacol. 2016;7:3303389-330.

53. Tam VH, Ledesma KR, Bowers DR, Zhou J, Truong LD. Kidney injury associated with telavancin dosing regimen in an animal model. Antimicrob Agents Chemother. 2015;59:2930-3.

54. Wong SL, Sörgel F, Kinzig M, Goldberg MR, Kitt MM, Barriere SL. Lack of pharmacokinetic drug interactions following concomitant administration of telavancin with aztreonam or piperacillin/tazobactam in healthy participants. J Clin Pharmacol. 2009;49:816-23. 
55. Wong SL, Goldberg MR, Ballow CH, Kitt MM, Barriere SL. Effect of Telavancin on the pharmacokinetics of the cytochrome P450 3A probe substrate midazolam: a randomized, doubleblind, crossover study in healthy subjects. Pharmacotherapy. 2010;30:136-43.

56. Farrell DJ, Mendes RE, Rhomberg PR, Jones RN. Revised reference broth microdilution method for testing telavancin: effect on MIC results and correlation with other testing methodologies. Antimicrob Agents Chemother. 2014;58:5547-51.

57. Mendes RE, Farrell DJ, Sader HS, Streit JM, Jones RN. Update of the telavancin activity in vitro tested against a worldwide collection of Gram-positive clinical isolates (2013), when applying the revised susceptibility testing method. Diagn Microbiol Infect Dis. 2015;81:275-9.

58. Zhanel GG, Adam HJ, Baxter MR, et al. Antimicrobial susceptibility of 22746 pathogens from Canadian hospitals: results of the CANWARD 2007-11 study. J Antimicrob Chemother. 2013;68(Suppl 1):i7-22.

59. Nichol KA, Adam HJ, Laing N, Weshnoweski B, Vashisht R, Baxter MR, et al. Activity of telavancin against Gram-positive cocci from CANWARD 2007-2013 using previously established and revised CLSI guidelines. In: 54th Interscience Conference on Antimicrobial Agents and Chemotherapy; 5-9 Sep 2014; Washington, DC.

60. Sweeney D, Shinabarger DL, Arhin FF, Belley A, Moeck G, Pillar CM. Comparative in vitro activity of oritavancin and other agents against methicillin-susceptible and methicillin-resistant Staphylococcus aureus. Diagn Microbiol Infect Dis. 2017;87:121-8.

61. Pace JL, Krause K, Johnston D, et al. In vitro activity of TD6424 against Staphylococcus aureus. Antimicrob Agents Chemother. 2003;47:3602-4.

62. King A, Phillips I, Kaniga K. Comparative in vitro activity of telavancin (TD-6424), a rapidly bactericidal, concentration-dependent anti-infective with multiple mechanisms of action against Gram-positive bacteria. J Antimicrob Chemother. 2004;53(5):797-803. https://doi.org/10.1093/jac/dkh156.

63. Andes D, Craig WA. In vivo pharmacodynamic activity of the glycopeptide dalbavancin. Antimicrob Agents Chemother. 2007;51:1633-42.

64. Biavasco F, Vignaroli C, Lupidi R, Manso E, Facinelli B, Varaldo PE. In vitro antibacterial activity of LY333328, a new semisynthetic glycopeptide. Antimicrob Agents Chemother. 1997;41:2165-72.

65. Larsson AJ, Walker KJ, Raddatz JK, Rotschafer JC. The concentration-independent effect of monoexponential and biexponential decay in vancomycin concentrations on the killing of Staphylococcus aureus under aerobic and anaerobic conditions. J Antimicrob Chemother. 1996;38:589-97.

66. Rybak MJ. The pharmacokinetic and pharmacodynamic properties of vancomycin. Clin Infect Dis. 2006;42:S35-9.

67. Odenholt I, Löwdin E, Cars O. In vitro studies of the pharmacodynamics of teicoplanin against Staphylococcus aureus, Staphylococcus epidermidis and Enterococcus faecium. Clin Microbiol Infect. 2003;9:930-7.

68. Bailey EM, Rybak MJ, Kaatz GW. Comparative effect of protein binding on the killing activities of teicoplanin and vancomycin. Antimicrob Agents Chemother. 1991;35:1089-92.

69. Peetermans WE, Hoogeterp JJ, Hazekamp-Van Dokkum AM, Van Den Broek P, Mattie H. Antistaphylococcal activities of teicoplanin and vancomycin in vitro and in an experimental infection. Antimicrob Agents Chemother. 1990;34:1869-74.

70. Ravizzola G, Pirali F, Foresti I, Turano A. Comparison of the in vitro antibacterial activity of teicoplanin and vancomycin against Gram-positive cocci. Drugs Exp Clin Res. 1987;13:225-9.

71. Odenholt I, Löwdin E, Cars O. Pharmacodynamic effects of telavancin against methicillin-resistant and methicillin-susceptible Staphylococcus aureus strains in the presence of human albumin or serum and in an in vitro kinetic model. Antimicrob Agents Chemother. 2007;51:3311-6.

72. MacGowan AP, Noel AR, Tomaselli S, Elliott HC, Bowker KE. Pharmacodynamics of telavancin studied in an in vitro pharmacokinetic model of infection. Antimicrob Agents Chemother. 2011;55:867-73.

73. Lepak AJ, Zhao M, Andes DR. Comparative pharmacodynamics of telavancin and vancomycin in the neutropenic murine thigh and lung infection models against Staphylococcus aureus. Antimicrob Agents Chemother. 2017. https://doi.org/10.1128/ AAC.00281-17.

74. Rybak MJ, Lomaestro BM, Rotschafer JC, Moellering RC, Craig WA, Billeter M, et al. Therapeutic monitoring of vancomycin in adults summary of consensus recommendations from the American Society of Health-System Pharmacists, the Infectious Diseases Society of America, and the Society of Infectious Diseases Pharmacists. Pharmacotherapy. 2009;29:1275-9.

75. Holmes NE, Turnidge JD, Munckhof WJ, et al. Vancomycin AUC/MIC ratio and 30-day mortality in patients with Staphylococcus aureus bacteremia. Antimicrob Agents Chemother. 2013;57:1654-63.

76. Brown J, Brown K, Forrest A. Vancomycin AUC 24/MIC ratio in patients with complicated bacteremia and infective endocarditis due to methicillin-resistant Staphylococcus aureus and its association with attributable mortality during hospitalization. Antimicrob Agents Chemother. 2012;56:634-8.

77. Moise-Broder PA, Forrest A, Birmingham MC, Schentag JJ. Pharmacodynamics of vancomycin and other antimicrobials in patients with Staphylococcus aureus lower respiratory tract infections. Clin Pharmacokinet. 2004;43:925-42.

78. Leonard SN, Supple ME, Gandhi RG, Patel MD. Comparative activities of telavancin combined with nafcillin, imipenem, and gentamicin against Staphylococcus aureus. Antimicrob Agents Chemother. 2013;57:2678-83.

79. Tängdén T, Hickman RA, Forsberg P, Lagerbäck P, Giske CG, Cars O. Evaluation of double- and triple-antibiotic combinations for VIM- and NDM-producing klebsiella pneumoniae by in vitro time-kill experiments. Antimicrob Agents Chemother. 2014;58:1757-62.

80. Lin G, Pankuch GA, Ednie LM, Appelbaum PC. Antistaphylococcal activities of telavancin tested alone and in combination by time-kill assay. Antimicrob Agents Chemother. 2010;54:2201-5.

81. Leonard SN, Vidaillac C, Rybak MJ. Activity of telavancin against Staphylococcus aureus strains with various vancomycin susceptibilities in an in vitro pharmacokinetic/pharmacodynamic model with simulated endocardial vegetations. Antimicrob Agents Chemother. 2009;53:2928-33.

82. Yim J, Smith JR, Barber KE, Hallesy JA, Rybak MJ. Evaluation of pharmacodynamic interactions between telavancin and aztreonam or piperacillin/tazobactam against Pseudomonas aeruginosa, Escherichia coli and methicillin-resistant Staphylococcus aureus. Infect Dis Ther. 2016;5:367-77.

83. Greenlee-Wacker MC, Rigby KM, Kobayashi SD, Porter AR, DeLeo FR, Nauseef WM. Phagocytosis of Staphylococcus aureus by human neutrophils prevents macrophage efferocytosis and induces programmed necrosis. J Immunol. 2014;192:4709-17. 
84. Reilly SS, Hudson MC, Kellam JF, Ramp WK. In vivo internalization of Staphylococcus aureus by embryonic chick osteoblasts. Bone. 2000;26:63-70.

85. Ellington JK, Reilly SS, Ramp WK, Smeltzer MS, Kellam JF, Hudson MC. Mechanisms of Staphylococcus aureus invasion of cultured osteoblasts. Microb Pathog. 1999;26:317-23.

86. Bosse M, Gruber H, Ramp W. Internalization of bacteria by osteoblasts in a patient with recurrent, long-term osteomyelitis. A case report. J Bone Jt Surg Am. 2005;87(6):1343-7. https:// doi.org/10.2106/JBJS.D.02649.

87. Lehar SM, Pillow T, Xu M, et al. Novel antibody-antibiotic conjugate eliminates intracellular $S$. aureus. Nature. 2015;527:323-8.

88. Seral C, Van Bambeke F, Tulkens PM. Quantitative analysis of gentamicin, azithromycin, telithromycin, ciprofloxacin, moxifloxacin, and oritavancin (LY333328) activities against intracellular Staphylococcus aureus in mouse J774 macrophages. Antimicrob Agents Chemother. 2003;47:2283-92.

89. Barcia-Macay M, Seral C, Mingeot-Leclercq M-P, Tulkens PM, Van Bambeke F. Pharmacodynamic evaluation of the intracellular activities of antibiotics against Staphylococcus aureus in a model of THP-1 macrophages. Antimicrob Agents Chemother. 2006;50:841-51.

90. Lemaire S, Kosowska-Shick K, Julian K, Tulkens PM, Van Bambeke F, Appelbaum PC. Activities of antistaphylococcal antibiotics towards the extracellular and intraphagocytic forms of Staphylococcus aureus isolates from a patient with persistent bacteraemia and endocarditis. Clin Microbiol Infect. 2008;14:766-77.

91. Nguyen HA, Denis O, Vergison A, Tulkens PM, Struelens MJ, Van Bambeke F. Intracellular activity of antibiotics in a model of human THP-1 macrophages infected by a Staphylococcus aureus small-colony variant strain isolated from a cystic fibrosis patient: study of antibiotic combinations. Antimicrob Agents Chemother. 2009;53:1443-9.

92. Van Bambeke F, Carryn S, Seral C, Chanteux H, Tyteca D, Mingeot-Leclercq M-P, et al. Cellular pharmacokinetics and pharmacodynamics of the glycopeptide antibiotic oritavancin
(LY333328) in a model of J774 mouse macrophages. Antimicrob Agents Chemother. 2004;48:2853-60.

93. Barcia-Macay M, Lemaire S, Mingeot-Leclercq MP, Tulkens PM, Van Bambeke F. Evaluation of the extracellular and intracellular activities (human THP-1 macrophages) of telavancin versus vancomycin against methicillin-susceptible, methicillin-resistant, vancomycin-intermediate and vancomycin-resistant Staphylococcus aureus. J Antimicrob Chemother. 2006;58:1177-84.

94. Barcia-macay M, Mouaden F, Mingeot-Leclercq MP, Tulkens PM, Van bambeke F. Cellular pharmacokinetics of telavancin, a novel lipoglycopeptide antibiotic, and analysis of lysosomal changes in cultured eukaryotic cells (J774 mouse macrophages and rat embryonic fibroblasts). J Antimicrob Chemother. 2008;61:1288-94.

95. Ye Z-K, Chen Y-L, Chen K, et al. Therapeutic drug monitoring of vancomycin: a guideline of the Division of Therapeutic Drug Monitoring, Chinese Pharmacological Society. J Antimicrob Chemother. 2016;71:3020-5.

96. Masuda N, Maiguma T, Komoto A, Haruki Y, Sugiyama T, Kondo S, et al. Impact of pharmacist intervention on preventing nephrotoxicity from vancomycin. Int J Clin Pharmacol Ther. 2015;53:284-91.

97. Jones RN. Microbial etiologies of hospital-acquired bacterial pneumonia and ventilator-associated bacterial pneumonia. Clin Infect Dis. 2010;51(Suppl 1):S81-7.

98. Stryjewski ME, Graham DR, Wilson SE, et al. Telavancin versus vancomycin for the treatment of complicated skin and skin-structure infections caused by Gram-positive organisms. Clin Infect Dis. 2008;46:1683-93.

99. Rubinstein E, Lalani T, Corey GR, et al. Telavancin versus vancomycin for hospital-acquired pneumonia due to gram-positive pathogens. Clin Infect Dis. 2011;52:31-40.

100. Wilson SE, Graham DR, Wang W, Bruss JB, Castaneda-Ruiz B. Telavancin in the treatment of concurrent Staphylococcus aureus bacteremia: a retrospective analysis of ATLAS and ATTAIN studies. Infect Dis Ther. 2017;6(3):413-22. https://doi. org/10.1007/s40121-017-0162-1. 